\title{
Detailed solvent, structural, quantum chemical study and antimicrobial activity of isatin Schiff base
}

\author{
Dominik R. Brkić $^{\mathrm{a}, *}$, Aleksandra R. Božić ${ }^{\mathrm{a}}$, Aleksandar D. Marinković ${ }^{\mathrm{b}}$, Miloš K. Milčić ${ }^{\mathrm{c}}$, Nevena Ž. Prlainović ${ }^{\mathrm{d}}$, \\ Fathi H. Assaleh ${ }^{\mathrm{e}}$, Ilija N. Cvijetić ${ }^{\mathrm{f}}$, Jasmina B. Nikolić ${ }^{\mathrm{b}}$, Saša Ž. Drmanić ${ }^{\mathrm{b}}$ \\ a Belgrade Polytechnic, Brankova 17, 11100 Belgrade, Serbia \\ ${ }^{\mathrm{b}}$ Faculty of Technology and Metallurgy, University of Belgrade, Karnegijeva 4, 11120 Belgrade, Serbia \\ c University of Belgrade - Faculty of Chemistry, Studentski trg 12-16, 11000 Belgrade, Serbia \\ d Innovation Center, Faculty of Technology and Metallurgy, University of Belgrade, Karnegijeva 4, 11120 Belgrade, Serbia \\ e Department of Chemistry, Faculty of Sciences, University of Zawia, P.O. Pox 16168, Zawia, Libya \\ ${ }^{\mathrm{f}}$ Innovation Center of the Faculty of Chemistry, University of Belgrade, Studentski trg 12-16, Belgrade, Serbia
}

\section{A R T I C L E I N F O}

\section{Article history:}

Received 10 October 2017

Received in revised form 13 December 2017

Accepted 30 January 2018

Available online 2 February 2018

\section{Keywords:}

E/Z isomers

Solvent effects

Substituent effects

Bader's analysis

TD-DFT, 3D QSAR

\begin{abstract}
A B S T R A C T
The ratios of $E / Z$ isomers of sixteen synthesized 1,3-dihydro-3-(substituted phenylimino)-2H-indol-2-one were studied using experimental and theoretical methodology. Linear solvation energy relationships (LSER) rationalized solvent influence of the solvent-solute interactions on the UV-Vis absorption maxima shifts $\left(\nu_{\max }\right)$ of both geometrical isomers using the Kamlet-Taft equation. Linear free energy relationships (LFER) in the form of single substituent parameter equation (SSP) was used to analyze substituent effect on $\mathrm{p} K_{\mathrm{a}}$, NMR chemical shifts and $v_{\max }$ values. Electron charge density was obtained by the use of Quantum Theory of Atoms in Molecules, i.e. Bader's analysis. The substituent and solvent effect on intramolecular charge transfer (ICT) were interpreted with the aid of time-dependent density functional (TD-DFT) method. Additionally, the results of TD-DFT calculations quantified the efficiency of ICT from the calculated charge-transfer distance $\left(D_{C T}\right)$ and amount of transferred charge $\left(\mathrm{Q}_{\mathrm{CT}}\right)$. The antimicrobial activity was evaluated using broth microdilution method. 3D QSAR modeling was used to demonstrate the influence of substituents effect as well as molecule geometry on antimicrobial activity.

(c) 2018 Elsevier B.V. All rights reserved.
\end{abstract}

\section{Introduction}

Isatin ( $1 \mathrm{H}$-indole-2,3-dione) and its metabolites are components of many natural substances. Chemistry of isatin and its derivatives as heterocyclic compounds is particularly interesting because of their wide application in medicinal chemistry. Isatin is an integral part of many synthetic compounds used in medicine and displays a wide range of activities such as antiviral [1], anticancer [2], antimicrobial [3], antibacterial [4], antitubercular [5], anti-fungal [6], anticonvulsant [7] and others. Isatin is also a core constituent of many alkaloids [8], dyes [9], insecticides [10] and analytical reagents [11].

It is known that isatin derivatives, as Schiff bases, show $E / Z$ isomerisation caused by the presence of imino group. $\beta$-Phenylethylamines such as tyramine in reaction with isatin form the mixtures of the two possible stereoisomers ( $E$ and $Z$ ) which can be thermodynamically or kinetically controlled. The assignation from NMR spectra indicated that major product was $E$ isomers. The largest amount of obtained isomer contained the higher amount of energy (lower stability). The ratio of the integrals in ${ }^{1} \mathrm{H}$ NMR spectra pointed to the

\footnotetext{
* Corresponding author.

E-mail address: dbrkic@politehnika.edu.rs (D.R. Brkić).
}

conclusion that the isomers were obtained in a $5: 1$ ratio $(E: Z)$. Such pattern resulted in conclusion that $E$ isomer is the kinetic product and $Z$ isomer is the thermodynamic product [12].

In some studies the ratios of $E$ and $Z$ isomer of 3-arylimino-2indolones isomers (1-benzyl-3-(4-methoxyphenylimino)indolin-2one) were investigated depending on the properties of solvent used. If DMSO is used as a solvent the $E$ isomer was most dominant was $(E: Z$ $=79: 21)$ while in toluene ratio of $E$ and $Z$ isomer was similar $(E: Z=$ 58:42) [13]. Results from NMR analysis of (E)-3-(3,4-dimethylphenyl) imino-1-methylindol-2-one has shown that dissolution of $E$-isomer is followed by partial isomerization to $Z$-form. The quantum chemical calculations of investigated compound showed that the more stable form in vacuum is $Z$-isomer, while change to the solvent of higher polarity lead to the stabilization of $E$-form. In the solvent of lower polarity, e.g. chloroform, $Z$ isomer is of higher stability, while with a change to the more polar solvent with higher dielectric constant such dichloroethane, acetone, methanol, acetonitrile, DMSO and water, $E$ isomer becomes more stable due to solvent stabilization [14]. Also, the mechanism of photochemically and thermally initiated $E$ - and Z-isomer transformations in solvents of different polarity, was investigated on two isatin $\mathrm{N}$-phenylsemicarbazone colorimetric sensors [15]. In other studies, the photochemical (irradiation) and thermal treatment of the $E$-isomers of 
isatin $N^{2}$-diphenylhydrazones leads to the transformation to Z-isomers in a reversible process [16].

In our previous study, LSER and LFER and quantum-chemical calculations related to isatin derivatives [17] were performed. In this work sixteen compounds were synthesized (Fig. 1, Table S3), and fully characterized with respect to $E / Z$ isomer ratio present in obtained products. Influence of solvent/solute interactions and substituent effects on the $\mathrm{p} K_{\mathrm{a}}$, NMR shifts or $\nu_{\max }$ values of $E$ and $Z$ isomers were analyzed by the use of LSER and LFER models. A detailed study on the relative stability of $E$ and $Z$ isomers computational techniques was performed to support experimental findings. Geometries of compounds were optimized by MP2 calculations. TD-DFT methodology was applied for assessment of the transition energy and evaluation of intramolecular charge transfer (ICT) processes. Additionally, to get better insight in relationships between structure of investigated isatin derivatives and their antimicrobial activity quantitative structure-activity relationships (QSAR) models were proposed.

\section{Experimental}

\subsection{Materials}

All used materials and solvents (UV spectrophotometric grade) were obtained from Sigma-Aldrich, and used without purification.

\subsection{Synthesis and Characterization of Isatin Derivatives}

General method applied for sixteen isatin derivatives preparation, is presented on Fig. 1 and described in Supplementary material [17]. The list of synthesized compounds and their elemental analysis are given in Table S3, while FTIR data in Table S4. Yield, melting points, ${ }^{1} \mathrm{H}$ and ${ }^{13} \mathrm{C}$ NMR analysis of obtained isatin derivatives are given in Table S5. Example of ${ }^{1} \mathrm{H}$ and ${ }^{13} \mathrm{C}$ NMR, COSY, NOESY, ${ }^{1} \mathrm{H}-{ }^{13} \mathrm{C}$ HSQC and ${ }^{1} \mathrm{H}-{ }^{13} \mathrm{C}$ HMBC for compound $\mathbf{1 0}$ are given in Figs. S2-S7, respectively.

The UV absorption spectra were measured in the range from 200 to $600 \mathrm{~nm}$ in sixteen solvents of different polarity by using UV/Vis Shimadzu 1700A spectrophotometer. The UV-Vis spectra were recorded at $25{ }^{\circ} \mathrm{C}$, in order to study the substituent effects on the solvatochromism of investigated compounds. The concentration of all solutions was $1.00 \times 10^{-5} \mathrm{~mol} \mathrm{~L}^{-1}$.

\subsection{Determination of the Acidity Constants of Studied Compounds}

Acidity constants of isatin derivatives were determined by spectrophotometric titration at $T=298 \pm 1 \mathrm{~K}$. The working solution $(c=9$ $\times 10^{-4} \mathrm{~mol} \mathrm{~L}^{-1}$ ) was prepared by dissolving an accurately weighed dried substance in $10.00 \mathrm{~mL}$ of DMSO; $10 \mathrm{mmol}^{-1}$ phosphate buffer $(p \mathrm{H}=6.00 \pm 0.02, I=0.1 \mathrm{M} \mathrm{NaCl})$ was added up to $100 \mathrm{~mL}$. Small volume increments of $1 \mathrm{M} \mathrm{KOH}$ were added stepwise, until $\mathrm{pH} 13.00$ \pm 0.02 was reached (total volume change at the end of the titration was lower than $2 \%$ ). The $\mathrm{pH}$ value was continuously measured during the titration and UV-Vis spectra recorded after $p H$ value equilibration. The UV-Vis spectra were recorded against the phosphate buffer as a blank. The $p \mathrm{H}$ electrode was calibrated by standard buffer solutions

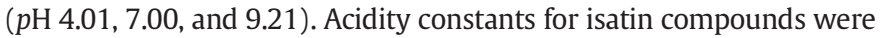
calculated according to transformed forms of classical spectrophotometric equations (Eqs. (1) and (2)) $[18,19]$ which give linear dependence (Eqs. (1a) and (2a)):

$A=A_{\mathrm{H}_{2} \mathrm{~A}^{+}}+\frac{A_{\mathrm{HA}}-A}{\left[\mathrm{H}_{3} \mathrm{O}^{+}\right]} \cdot K_{\mathrm{a} 1}$,

or

$\left(A-A_{\mathrm{HA}}\right) \cdot 10^{p H}=\frac{A_{\mathrm{H}_{2} \mathrm{~A}^{+}}}{K_{\mathrm{a} 1}}-\frac{1}{K_{\mathrm{a} 1}} A$

$A=A_{\mathrm{A}^{-}}+\left(A_{\mathrm{HA}}-A\right) \cdot\left[\mathrm{H}_{3} \mathrm{O}^{+}\right] \cdot \frac{1}{K_{\mathrm{a} 2}}$,

or

$\left(A-A_{\mathrm{HA}}\right) \cdot 10^{p H}=K_{\mathrm{a} 2} \cdot A_{\mathrm{A}^{-}}-K_{\mathrm{a} 2} \cdot A$

where $A$ represents absorbance of certain species $\left(\mathrm{H}_{2} \mathrm{~A}^{+}, \mathrm{HA}\right.$, or $\left.\mathrm{A}^{-}\right)$labeled as subscripts, and $K_{\mathrm{a} 1}$ and $K_{\mathrm{a} 2}$ represent the first and second dissociation constant of isatin derivatives, respectively.

\subsection{LSER Analysis}

Quantification of the solvent effects: non-specific, i.e. dipolarity/polarizability, and specific ones, hydrogen-bonding ability, on the $\nu_{\max }$ were interpreted using LSER principles, i.e. Kamlet-Taft Eq. (3) [20]:

$v_{\max }=\nu_{0}+s \pi^{*}+b \beta+a \alpha$

where $v_{\max }$ is substituent-dependent values, i.e., absorption frequencies, $\pi^{*}$ is an index of the solvent dipolarity/polarizability; $\beta$ is a measure of the solvent hydrogen-bond acceptor (HBA) basicity; $\alpha$ is a measure of the solvent hydrogen-bond donor (HBD) acidity and $v_{o}$ is the regression value in cyclohexane as reference solvent. The solvent parameters used in Eq. (3) are given in Table S1. The regression coefficients $s, b$ and $a$ in Eq. (3) measure the relative susceptibilities of the absorption frequencies to the different solvent parameters. This method provided the tools for detailed analysis of solvent effect on $v_{\max }$.

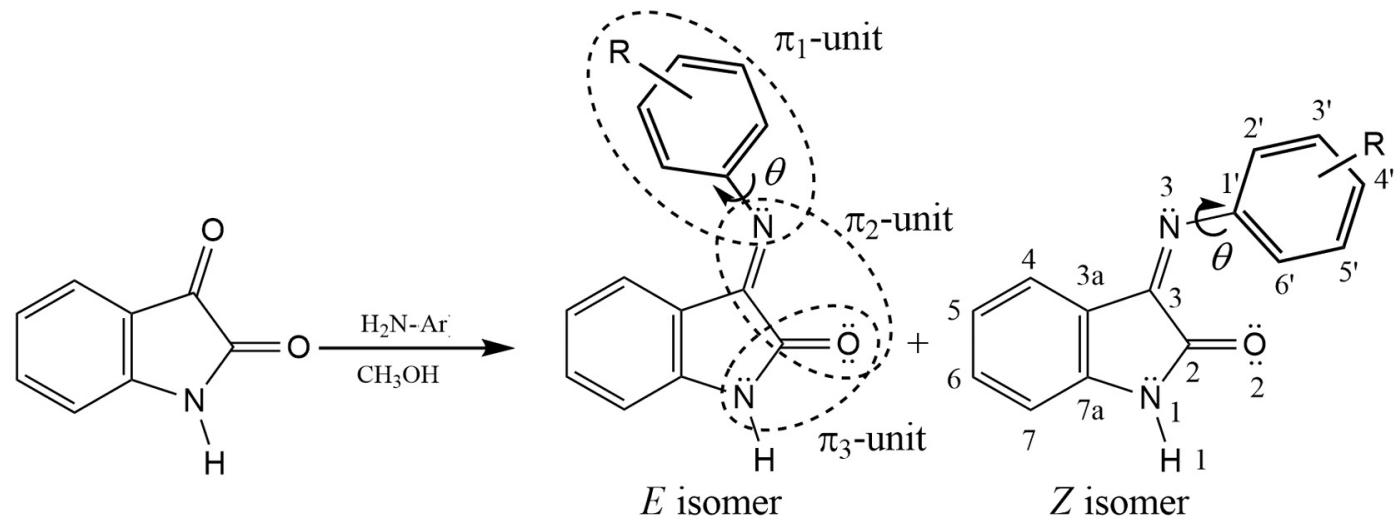

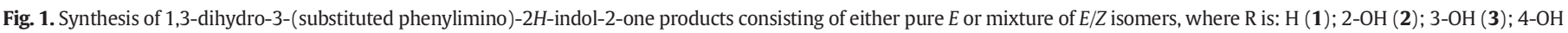

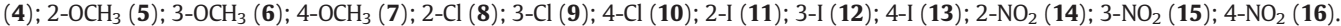




\subsection{LFER Analysis}

The LFER analysis, related to the transmission of polar (field/inductive) and resonance substituent effects, were applied to the $\mathrm{p} K_{\mathrm{a}}, \mathrm{UV}$ and NMR data of the studied compounds (Fig. S1) by using Hammett Eq. (4) (SSP):

$s=\rho \sigma+h$

where $s$ are substituent-dependent values: $\mathrm{p} K_{\mathrm{a}}$, NMR or $v_{\text {max }} ; \rho$ is a proportionality constant (reaction constant) reflecting the sensitivity of the spectral data to the substituent effects; $\sigma$, is the substituent constants (Table S2), and $h$ is the intercept (i.e., it describes the unsubstituted member of the series) [21,22]. SSP equation attributes to the contribution of both polar and $\pi$-delocalization effects given as $\sigma$ values.

\subsection{Antimicrobial Activity}

Minimum inhibitory concentrations (MIC) of the compounds were determined using broth microdilution method, according to CLSI 2005 $[23,24]$. Antimicrobial activity was tested against 7 bacterial and 2 fungal strains of the American Type Culture Collection (ATCC): Staphylococcus aureus 6538, Listeria monocytogenes 19,115, Shigella sonnei 29,930, Yersinia enterocolitica 27,729, Escherichia coli 25,922, Proteus hauseri 13,315, Pseudomonas aeruginosa 9027, Cryptococcus neoformans 76484 and Candida albicans 10231. Microbial density was set at 105 colony forming units. The antimicrobial assay was performed in 96-well microtiter plates (Sarstedt, Germany). Compounds were dissolved in 5\% DMSO aqueous solution, covering the range of concentrations from 0.6 to $1250 \mu \mathrm{g} / \mathrm{mL}$. Triphenyltetrazolium chloride (0.0075\%) was added to bacterial suspension as a growth indicator. Positive growth control was $5 \%$ DMSO in appropriate medium. All bacterial strains were incubated $24 \mathrm{~h}$ at $37^{\circ} \mathrm{C}$, while yeast strains were incubated $48 \mathrm{~h}$ at $32{ }^{\circ} \mathrm{C}$. The compound concentration at which there was no visible microbial growth was taken as MIC value. Amoxicillin trihydrate and fluconazole were used as standards for bacterial and fungal strains, respectively.

\subsection{Molecular Geometry Optimization and Theoretical Absorption Spectra Calculation}

The ground state geometries of booth isomers ( $E$ and $Z$ ) of compounds 1-16 were optimized with MP2 method. First, the conformational search, for every isomer, was conducted in order to find optimal value for angle $\theta$ using MP2 method with double-zeta quality basis set, $6-31 \mathrm{G}(\mathrm{d}, \mathrm{p})$. After that, conformer with lowest energy was reoptimized using the same method but with larger $6-311 \mathrm{G}(\mathrm{d}, \mathrm{p})$ basis set. For iodine atom (compounds 11, 12 and 13) a specially designed basis set of 6311G quality, with added supplementary functions was used [25]. Global minima were found for each optimized compound and was confirmed by calculations of harmonic vibrational frequencies (no imaginary frequency were found).

Theoretical absorption spectra of both tautomeric forms were calculated in gas phase, ethanol, tetrahydrofuran and dimethylsulfoxide with TD-DFT method, more specifically with CAM-B3LYP long range corrected functional [26] and 6-311G(d,p) basis set on MP2/6-311G(d, p) gas phase optimized geometries. Solvents in the TD-DFT calculations were simulated with standard polarized continuum model (PCM) [27].

Qualitative charge transfer indices: the charge-transfer distance $\left(D_{\mathrm{CT}}\right)$, amount of transferred charge $\left(\mathrm{Q}_{\mathrm{CT}}\right)$, were evaluated according to method proposed by [28]. All quantum chemical calculations were carried out using the Gaussian09 program [29]. The Bader's analysis were done on charge density grid with program "Bader" [30]. Density difference maps were plotted as difference between electron densities of the first excited state and the ground state, in program gOpenMol [31].

\subsection{D QSAR Model}

As the independent variables, we used the GRIND-2 descriptors derived from molecular interaction fields (MIFs) [32]. Pentacle software v. 1.06 [33] was used to compute the GRIND-2 descriptors, and perform partial least square regression (PLS) analysis.

MIFs were calculated using four chemical probes: DRY probe, which maps the hydrophobic regions of a molecule; $\mathbf{O}$ is $s p^{2}$ carbonyl probe that discovers the regions of a molecule with $\mathrm{H}$-bond donor ability; $\mathbf{N 1}$ is neutral flat -NH that maps the H-bond acceptors of molecules, and TIP probe encodes the shape of a molecule. Important positions around molecules (hot spots) are extracted from MIFs using AMANDA discretization algorithm [34]. Encoding of the filtered MIFs into GRIND variables was performed by the maximal auto- and cross-correlation (MACC2) algorithm. Obtained hot spots represent the 3D position of favorable pharmacophoric points of molecules, and shape the virtual receptor site (VRS). Grid step size is reduced to $0.4 \AA$ to increase the resolution. All other parameters for MIF computation were as default.

The choice of optimal conformation is a critical step in 3D QSAR modeling. In cases when we know the exact molecular target, docking of compounds into the active site could give a proper, "bioactive" conformation. In this case, we do not know the exact target(s) for any of microbial strains tested, so we generated the conformation of each molecule by the systematical change of a torsion angle $\theta$ by $30^{\circ}$ and energy minimization of each rotamer using semiempirical PM6 method implemented in MOPAC 2016 [35]. The lowest energy conformer of each compound was used for further calculation of MIFs. VEGA ZZ 3.1.0 was used as a GUI [36].

\section{Results and Discussion}

\subsection{Chemistry}

The condensation of selected anilines and isatin at 1:1 $\mathrm{M}$ ratio were used for the syntheses of 1,3-dihydro-3-(substituted phenylimino)-2Hindol-2-ones (Fig. 1). ${ }^{1} \mathrm{H}$ and ${ }^{13} \mathrm{C}$ NMR, FTIR and elemental analysis data of synthesized compounds 1-16 are given in Supplementary material. In the infrared spectrum of the studied compounds the absorptions between 1602 and $1747 \mathrm{~cm}^{-1}$ were assigned to the $v(C 2=0)$ and $v(\mathrm{C} 3=\mathrm{N})$ stretching vibrations, respectively, while the absorption between 3124 and $3463 \mathrm{~cm}^{-1}$ is attributed to the $v\left(\mathrm{NH}_{2}\right)$ vibration.

In the ${ }^{13} \mathrm{C}$ NMR spectra of all studied compounds, the numbers of the signals match exactly the number of carbon atoms. Elemental analysis results were within $\pm 0.4 \%$ of the theoretical values.

It is known that imino compounds can adopt $E$ - or Z-configuration around the $\mathrm{C}=\mathrm{N}$ double bond and that the chemical environment of the azomethine carbon (C3) is different for studied isomer [37,38]. Investigated isatin derivatives showed chemical shift of the azomethine carbon in the range of $150.43-156.72$ for $E$ isomer, and 150.90-155.16 for $Z$ isomer listed in Table S6.

The stereochemistry of the imines was undoubtedly established using 2D homonuclear (COSY and NOESY) and heteronuclear (HSQC and HMBC) NMR techniques. As an example, the chemical shifts of compounds 10 were assigned by a combined use of one-dimensional $\left({ }^{1} \mathrm{H}\right.$ and ${ }^{13} \mathrm{C}$ proton decoupled, Figs. S2 and S3), and two-dimensional NMR experiments COSY, NOESY, HSQC and HMBC given on Figs. S4-S7, respectively. In order to assess conformation of $\mathbf{1 0}$ in a solution, two-dimensional NOESY sequence was applied (Fig. S5). The $E$ stereochemistry was assigned to be major isomer in DMSO $d_{6}$ solutions because the NOESY experiments show proximity of $\mathrm{C} 4-\mathrm{H}$ and $\mathrm{C}^{\prime}-\mathrm{H}$ atoms (Fig. S5).

In addition, the signal for $\mathrm{H} 1$ of the $E$-isomer was considerably shifted upfield (approx. $1 \mathrm{ppm}$ ) relative to the $\mathrm{H} 1$ signal of the parent isatin. Moreover, the chemical shifts of the proton present in Z-isomer showed little difference to those found in parent compound, isatin (see Supplementary data). The 7.5:2.5 isomer ratio for compound $\mathbf{1 0}$ 
in DMSO $d_{6}$ was obtained from ${ }^{1} \mathrm{H}$ NMR spectrum (Fig. S2). Analogously, the analyses of $1 \mathrm{H}$ NMR data of N1-H1 proton were used for calculation of $E / Z$ isomer ratio of other studied compounds (Tables $S 5$ and S6). The obtained results showed that $E$ form dominate in DMSO solution irrespectively to the electronic influences of substituents. Four compounds with 2 - and $4-\mathrm{NO}_{2}$, and $3-\mathrm{OH}$ and $3-\mathrm{OCH}_{3}$ group showed only presence of $E$ isomer. On the other hand, the influences of electron-donating groups induce stabilization of $Z$ isomer. Such properties could contribute to the change of physico-chemical characteristics and to the differences in biological activity within these compounds as a function of varying isomer compositions. As a continuation of the presented work, determination of acidity constants and detailed analysis of solvent effect on equilibria of isomeric isatin derivatives was carried out using UV-Vis spectroscopy.

\subsection{Determination of Acidity Constants}

The acidity constants were determined using spectrophotometric titration of investigated compounds at $T=298 \pm 1 \mathrm{~K}$. As an example, $\mathrm{UV}-\mathrm{Vis}$ spectra of compound $\mathbf{1 6}\left(4-\mathrm{NO}_{2}\right)$ in $\mathrm{pH}$ range $7.60-12.52$ are shown in Fig. 2.

Within the studied $\mathrm{pH}$ range (6.02-12.92) the predicted protolytic equilibria of isatin derivatives in aqueous media are shown on Figs. S8 and S9. The corresponding distribution diagrams are given on Figs. S10 and S11.

In hydroxy substituted compounds two $\mathrm{p} K_{\mathrm{a}}$ values were obtained corresponding to dissociation of proton on oxygen ( $\mathrm{pH}$ 8.00-9.00) and isatin nitrogen ( $\mathrm{pH} 9.68-12.11)$. Acidity constants, $K_{\mathrm{a}}, K_{\mathrm{a} 1}$ and $K_{\mathrm{a} 2}$ values, were calculated according to the linearized forms of Eqs. (1a) and (2a) [18]. Values of $K_{\mathrm{a}}$ and the ones for hydroxy substituted compounds $K_{\mathrm{a} 2}$ were obtained as the slope of the corresponding linear dependencies at two wavelengths (around 300 and $370 \mathrm{~nm}$ ), while $K_{\mathrm{a} 1}$ was obtained as the slope of the corresponding linear dependencies at two wavelengths (around $500 \mathrm{~nm}$ ). Example the calculation of $K_{\mathrm{a}}$ for compound 16 is shown on Fig. S12.

The obtained $\mathrm{p} K_{\mathrm{a}}, \mathrm{p} K_{\mathrm{a} 1}$ and $\mathrm{p} K_{\mathrm{a} 2}$ values are given in Table 1 . As shown in Figs. $S 8$ and $\mathrm{S} 9, K_{\mathrm{a}}$ and $K_{\mathrm{a} 2}$ represents the dissociation of the amide N-H hydrogen, while $K_{\mathrm{a} 1}$ corresponds for the dissociation of the hydroxy substituted isatins (Fig. S9).

Variation of the values of ionization constants showed dependence on electronic substituent effects, as well as appropriate contribution of steric effect in compounds $\mathbf{2 , 5 , 8}$ and 11. Similar $\mathrm{p} K_{\mathrm{a}}$ and $p \mathrm{~K}_{\mathrm{a} 2}$ values of compounds 15 and $\mathbf{1 6}$, with respect to 3 and $\mathbf{4}$, showed unexpected behavior considering transmission mode of substituent effects through

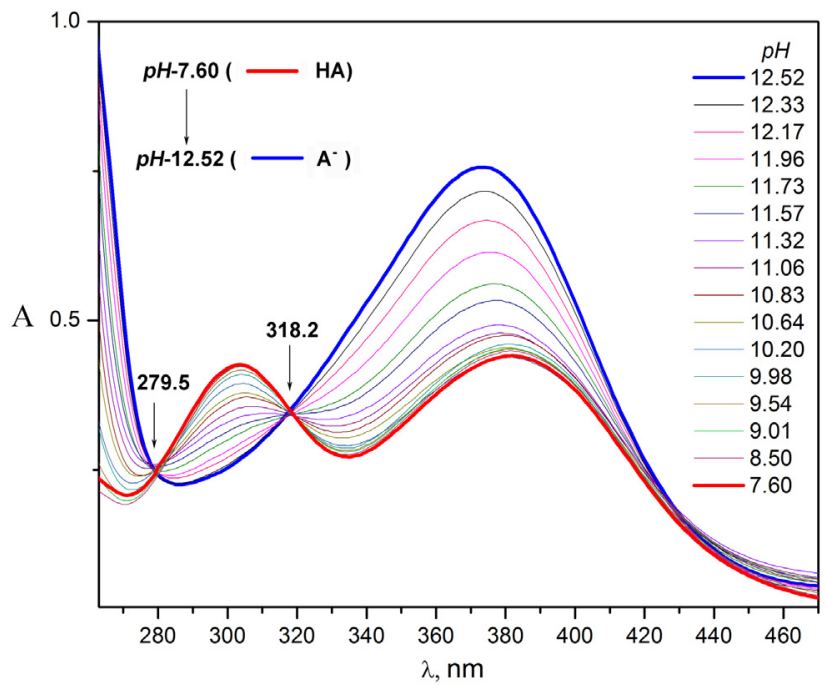

Fig. 2. UV-Vis spectra of compound $\mathbf{1 6}$ in pH range $7.60-12.52$ at $25^{\circ} \mathrm{C}$.
Table 1

Experimental $p K_{\mathrm{a}}$ values of investigated isatin derivatives.

\begin{tabular}{llll}
\hline Compound/substituent & $p \mathrm{~K}_{\mathrm{a}}$ & $p \mathrm{~K}_{\mathrm{a} 1}$ & $p \mathrm{~K}_{\mathrm{a} 2}$ \\
\hline $\mathbf{1} / \mathrm{H}$ & 10.83 & & \\
$\mathbf{2} / 2-\mathrm{OH}$ & & 8.75 & 12.52 \\
$\mathbf{3} / 3-\mathrm{OH}^{\mathrm{a}}$ & & 8.62 & 11.92 \\
$\mathbf{4} / 4-\mathrm{OH}$ & & & 12.31 \\
$\mathbf{5} / 2-\mathrm{OMe}$ & 10.95 & & \\
$\mathbf{6} / 3-\mathrm{OMe}{ }^{\mathrm{a}}$ & 10.03 & & \\
$\mathbf{7} / 4-\mathrm{OMe}$ & 11.49 & & \\
$\mathbf{8} / 2-\mathrm{Cl}$ & 10.99 & & \\
$\mathbf{9} / 3-\mathrm{Cl}$ & 9.84 & & \\
$\mathbf{1 0} / 4-\mathrm{Cl}$ & 9.68 & & \\
$\mathbf{1 1} / 2-\mathrm{I}$ & 10.11 & & \\
$\mathbf{1 2} / 3-\mathrm{I}$ & 10.85 & & \\
$\mathbf{1 3} / 4-\mathrm{I}$ & 10.68 & & \\
$\mathbf{1 4} / 2-\mathrm{NO}_{2}{ }^{\mathrm{a}}$ & 11.09 & & \\
$\mathbf{1 5} / 3-\mathrm{NO}_{2}$ & 11.37 & & \\
$\mathbf{1 6} / 4-\mathrm{NO}_{2}{ }^{\mathrm{a}}$ & 11.12 & & \\
\hline
\end{tabular}

a $p \mathrm{~K}_{\mathrm{a}}$ determined for $E$ isomer, and for other mixture of isomer (defined in Table S6) were considered.

$\pi_{1}$ - and $\pi_{2}$-units (Fig. 1). Electron-donating capability of hydroxy group in compounds $\mathbf{2 - 4}$ contribute to slight decrease of $\mathrm{p} K_{\mathrm{a}}$ values. Unexpectedly high $\mathrm{p} K_{\mathrm{a}}$ values, vice versa lower acidity, of compounds 14$\mathbf{1 6}$, in comparison to $\mathbf{2 - 4}$, is a results of appropriate degree of the attenuation of the transmission of substituent effect through azomethine bond and competitive $\pi$-conjugative interactions in $\pi_{1}$ - and $\pi_{2}$-units (Fig. 1).

On the other hand, the value of ionization constant of compounds 513 behave in a regular fashion indicating that position-dependent influences of substituent effects is main contributing factor to changes of $\mathrm{p} K_{\mathrm{a}}$. As it can be seen, the trends of increasing of the $p \mathrm{~K}_{\mathrm{a}}$ in compounds 5-13, are followed by $\mathrm{p} K_{\mathrm{a}}$ values increase as electron-withdrawing capability of substituent increase.

The effect of extended conjugation through the azomethine bridging group could contribute to alternation of the transmission of substituent effects causing change of proton-donating/accepting properties of appropriate sites capable for dissociation. In order to understand/quantify the influence of structural effect/ionization constants of prospective sites at investigated molecule LFER analysis, using SSP Eq. (1), was performed. The correlation results of calculated $p \mathrm{~K}_{\mathrm{a}}$ and $p \mathrm{~K}_{\mathrm{a} 2}$ values (Table 1) with selected substituent constant (Table S2) are given in Table 2.

Obtained results clearly showed that relationship $\mathrm{p} K_{\mathrm{a}}$ versus $\sigma$ showed significant influence of both electron-accepting and electrondonating substituents effects to change of acidity of $\mathrm{N}-\mathrm{H}$ hydrogen on isatin ring. Reverse substituent effect on $\mathrm{p} K_{\mathrm{a}}$ values change means that increased electron-accepting power of substituent cause increase $\mathrm{p} K_{\mathrm{a}}$ value although $\sigma$ increases. Higher sensitivity of $\mathrm{p} K_{\mathrm{a}}$ to substituent effect was found in second series of compounds due to contribution of both steric and strong electron-accepting character of substituents.

\subsection{Solvent Effects on the UV Spectra}

Electronic properties of the isomeric forms of investigated isatin sensitively depends on solvent properties like polarity, stabilization of the charges in the solvation sphere and alteration of a solute's electronic structure in the ground and excited state due to both short- and longrange interactions with surrounding solvent molecules [17,39]. Additionally, geometries and substituent effects on the extent/intensity of solvent/solute interactions could be of appropriate significance.

Various spectroscopic techniques was used for studying the properties and state of equilibria/interconversion of geometrical isomers, mechanism of isomerisation and solvent-solute interactions dependent on structural properties of the studied isomers [3,40,41]. UV-Vis technique is a useful method for studying the spectral properties of geometrical isomers, their sensitivity to the solvent properties, substituent 
Table 2

Correlation results of the $p \mathrm{~K}_{\mathrm{a}}$ and $p \mathrm{~K}_{\mathrm{a} 2}$ values with $\sigma$ constants using SSP equation.

\begin{tabular}{|c|c|c|c|c|c|c|c|c|}
\hline & $\rho$ & & $h$ & $R$ & $F$ & sd & $n$ & Compounds included \\
\hline$p \mathrm{~K}_{\mathrm{a}}$ and $p \mathrm{~K}_{\mathrm{a} 2}$ & $(-1.01 \pm 0.26) \sigma^{2}$ & $(-2.56 \pm 0.19) \sigma$ & $10.92 \pm 0.07$ & 0.989 & 181.15 & 0.165 & 11 & $1,2,3,4,5,6,7,9,10,11,13$ \\
\hline$p \mathrm{~K}_{\mathrm{a}}$ & $(-2.84 \pm 0.46)$ & & $13.33 \pm 0.38$ & 0.974 & 37.49 & 0.081 & 4 & $8,14,15,16$ \\
\hline
\end{tabular}

effect, acidity, temperature, etc. In order to perform such study, the UVVis spectra were recorded at concentration of $1 \times 10^{-5} \mathrm{~mol} \mathrm{~L}^{-1}$, and characteristic absorption spectra of investigated compounds in DMSO and THF are shown in Fig. 3, and in ethanol are given in Fig. S13.

The absorption spectra of the investigated compounds, recorded in twenty-two solvents, showed that spectra consist of two bands at $\nu_{\max } \sim 300$ and $425 \mathrm{~nm}$ (Fig. 3). In order to resolve position of $v_{\max }$ corresponding to $E$ and $Z$ isomer it was necessary to apply TD-DFT calculation. TD-DFT was successfully used for studying of solvated molecules, electronic transition and evaluation of electronic density transfer $[42,43]$ Results of TD-DFT calculations provided the theoretical spectra of both $E$ and $Z$ isomers in DMSO, EtOH and AcN (Figs. S14 and S15, respectively). The absorption maxima of $Z$ appeared on higher wavelength (lower energy band) than $E$ form in all investigated solvents as well as in gas phase. Based on TD-DFT results, deconvolution of experimental spectra were performed, and examples of applied procedure are given for compounds 7 (4-OMe) and 12 (3-I) on Fig. S16. Validation of applied methodology was done on the basis of comparative study of the NMR analysis (Table S5), TD-DFT results and resolved experimental spectra in DMSO. After methodology verification, determination of absorption maxima corresponding to both forms was performed, and the obtained results are summarized in Tables 3 and S7, respectively.

The data from Table 3 and S7 confirm that the positions of the UVVis absorption frequencies depend on the nature of the substituent present. There is appropriate regularity in the $v_{\max }$ change where introduction of both electron-donating and electron-withdrawing substituents mainly contributes to the positive solvatochromism, comparing to the unsubstituted compound. On the other hand, appropriate
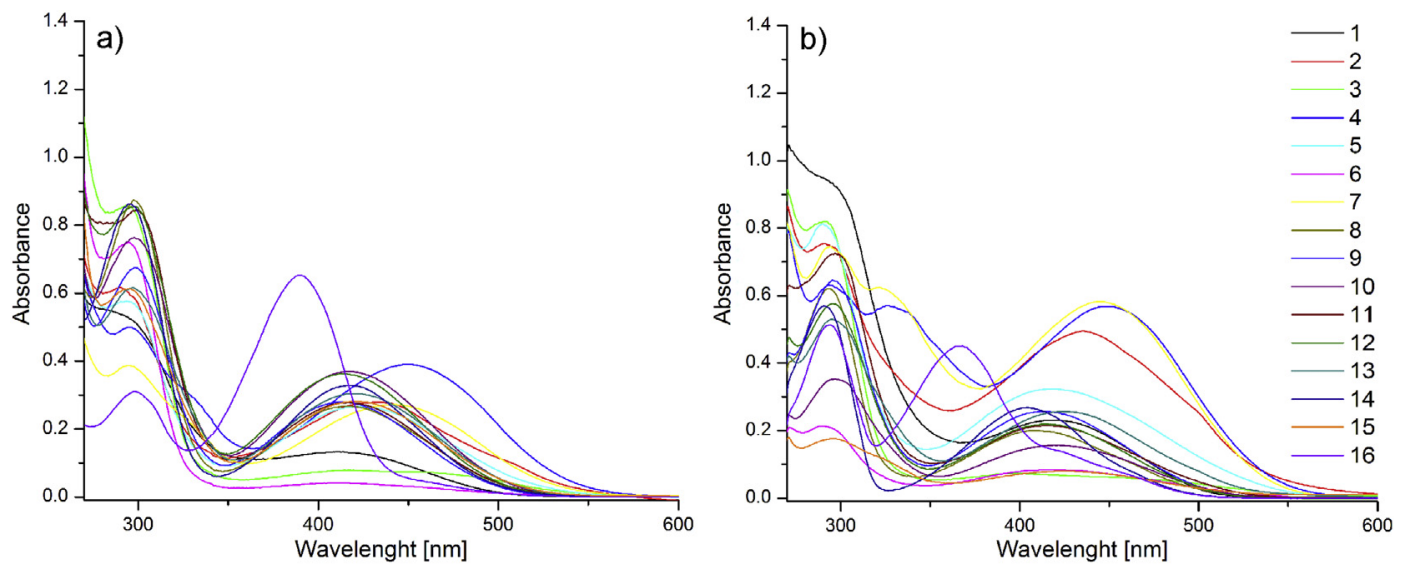

Fig. 3. Absorption spectra of compounds 1-16 in a) DMSO and b) THF.

Table 3

Absorption frequencies of isatin compounds in selected solvents for $E$ isomers.

\begin{tabular}{|c|c|c|c|c|c|c|c|c|c|c|c|c|c|c|c|c|}
\hline \multirow[t]{2}{*}{ Solvent/compound } & \multicolumn{16}{|c|}{$v_{\max } \times 10^{-3}\left(\mathrm{~cm}^{-1}\right)$} \\
\hline & 1 & 2 & 3 & 4 & 5 & 6 & 7 & 8 & 9 & 10 & 11 & 12 & 13 & 14 & 15 & 16 \\
\hline $\mathrm{MeOH}$ & 25.84 & 23.87 & 25.03 & 23.43 & 25.00 & 26.14 & 23.06 & 25.50 & 25.41 & 25.49 & 24.61 & 25.38 & 24.55 & 23.79 & 25.89 & 26.63 \\
\hline EtOH & 26.31 & 23.24 & 25.01 & 23.03 & 24.57 & 26.38 & 22.36 & 25.30 & 25.11 & 25.11 & 24.98 & 25.67 & 25.13 & 23.99 & 25.14 & 26.17 \\
\hline iPrOH & 25.60 & 23.53 & 27.91 & 22.92 & 24.14 & 23.18 & 22.53 & 24.77 & 25.05 & 24.58 & 24.99 & 25.13 & 24.85 & 23.83 & 24.57 & 25.81 \\
\hline 2-BuOH & 23.99 & 22.90 & 25.21 & 23.24 & 23.91 & 24.47 & 22.16 & 24.87 & 24.40 & 24.12 & 24.13 & 24.46 & 24.07 & 24.08 & 24.44 & 26.04 \\
\hline $\mathrm{ChOH}$ & 24.79 & 22.89 & 22.85 & 23.58 & 24.68 & 24.97 & 22.36 & 24.79 & 24.79 & 24.76 & 23.97 & 24.71 & 24.31 & 24.89 & 25.63 & 26.06 \\
\hline $\mathrm{BzOH}$ & 25.56 & 23.38 & 22.38 & 23.53 & 24.18 & 26.14 & 22.39 & 24.55 & 25.28 & 24.85 & 23.68 & 24.81 & 24.06 & 24.41 & 24.65 & 26.14 \\
\hline $2 \mathrm{ME}$ & / & 23.11 & / & 23.54 & 24.19 & / & 22.27 & 24.57 & 25.01 & 24.78 & 25.1 & 24.54 & 24.15 & 24.49 & 25.60 & 26.48 \\
\hline $2 \mathrm{CE}$ & 25.25 & 20.99 & 25.30 & 22.51 & 24.79 & 27.00 & 19.53 & 24.69 & 24.61 & 24.92 & 25.05 & 24.83 & 24.95 & 23.95 & 24.20 & 24.84 \\
\hline DME & 24.47 & 24.10 & 25.14 & 22.99 & 25.61 & 27.60 & 22.81 & 24.81 & 25.05 & 24.46 & 25.26 & 24.93 & 23.87 & 25.02 & 24.80 & 27.32 \\
\hline Toluene & 25.84 & 22.48 & 23.10 & 23.00 & 24.98 & 26.11 & 21.77 & 25.17 & 24.57 & 24.37 & 24.49 & 24.18 & 23.92 & 24.85 & 23.33 & 24.48 \\
\hline DCM & 25.64 & 22.63 & / & 24.48 & 24.42 & 24.93 & 21.87 & 24.99 & 24.90 & 24.73 & 24.79 & 24.86 & 24.56 & 21.53 & / & 25.10 \\
\hline Acetone & 24.70 & 23.75 & 26.20 & 23.43 & 25.33 & 25.39 & 22.65 & 24.74 & 24.96 & 24.64 & 24.48 & 24.49 & 24.05 & 24.81 & 23.63 & 27.05 \\
\hline ChO & 24.40 & 23.70 & 25.67 & 23.58 & 24.78 & 26.29 & 22.47 & 24.61 & 25.24 & 24.93 & 24.15 & 24.3 & 24.35 & 24.59 & 24.86 & 26.91 \\
\hline EtAc & 24.65 & 23.98 & 26.40 & 23.43 & 25.26 & 25.40 & 22.28 & 24.96 & 25.36 & 23.97 & 24.58 & 24.32 & 23.86 & 25.15 & / & 27.81 \\
\hline $\mathrm{F}$ & 25.34 & 23.33 & 24.32 & 23.04 & 24.66 & 24.61 & 22.67 & 24.90 & 25.36 & 25.27 & 24.59 & 25.55 & 24.94 & 23.67 & 24.36 & 25.67 \\
\hline DMF & 25.87 & 23.40 & 24.53 & 22.84 & 24.36 & 24.78 & 21.82 & 24.12 & 24.43 & 24.34 & 24.71 & 24.27 & 24.44 & 24.09 & 24.62 & 25.93 \\
\hline DMAc & 24.32 & 23.43 & 25.23 & 23.12 & 23.64 & 24.13 & 22.10 & 23.94 & 24.81 & 24.53 & 24.57 & 24.12 & 24.56 & 23.75 & 24.48 & 25.80 \\
\hline NMP & 24.08 & 23.25 & 24.91 & 21.96 & 24.21 & 24.55 & 21.95 & 23.98 & 24.86 & 24.59 & 24.46 & 24.61 & 24.74 & 23.88 & 24.67 & 25.81 \\
\hline $\mathrm{AcN}$ & 26.17 & 24.00 & 24.80 & 23.57 & 25.04 & 25.32 & 22.76 & 25.41 & 25.99 & 25.26 & 25.35 & 25.37 & 25.33 & 25.10 & 24.36 & 27.17 \\
\hline DMSO & 26.14 & 23.58 & 25.12 & 23.00 & 24.09 & 26.46 & 22.33 & 24.48 & 24.91 & 24.61 & 24.64 & 24.72 & 24.59 & 23.86 & 24.43 & 25.78 \\
\hline THF & 24.16 & 23.05 & 25.42 & 22.95 & 24.84 & 24.26 & 21.76 & 25.00 & 24.58 & 24.15 & 24.65 & 24.25 & 23.89 & 24.28 & 24.28 & 27.51 \\
\hline 2-Py & 24.96 & 23.16 & 24.28 & 23.08 & 24.13 & 25.35 & 22.01 & 24.01 & 24.79 & 24.93 & 23.97 & 25.13 & 24.66 & 23.98 & 24.48 & 25.85 \\
\hline
\end{tabular}


exception were found for compounds 6, 15 and 16 in $E$ isomer, and also for compound 14 in $Z$ isomer.

\subsection{LSER Analysis of UV Data}

The contribution of specific and nonspecific solvent-solute interactions was quantitatively evaluated by the use of LSER Eq. (3). The LSER concepts developed by Kamlet and Taft represent a successful methodology usually used for quantitative treatments of solvation effects. This treatment assumes attractive/repulsive solvent/solute interactions and enables an estimation of the extent of solvent/solute interactions. Correlation results obtained by the use Kamlet-Taft model are given in Table 4 for $E$ isomer, and Table $S 8$ for $Z$ isomer. The percentages contribution of the nonspecific $\left(P_{\pi}\right)$ and the specific solvent/solute interactions $\left(P_{\beta}\right.$ and $\left.P_{\alpha}\right)$ are also given in Tables 4 and S8.

The obtained correlations for $E$ and $Z$ isomer (Tables 4 and S8, respectively) display a significant influence of solvent and substituent effect on the change/variation of the solvatochromic coefficients. A negative sign of the coefficients $s$ and $a$, obtained in correlations for $E$ isomer for non-specific and HBD solvent effect (Table 4) indicate a batochromic shift of the absorption maxima with the increasing contribution of solvent dipolarity/polarizability and hydrogen-donating capability. Opposite sign were found for compounds 1, 6-10, 12 and 13 (coefficients $s$ ) and also compounds 1, 6-10, 12,13 and 15 (coefficient a). The largest values of coefficient $s(-3.66)$ and $a(-2.82)$ were found for compound 3 (Table 4). It means that the most effective transmission of the substituent effect, i.e. electron-donating ability of the hydroxy group (comp. 3), from meta-position to the isatin ring cause higher susceptibility of electronic density to solvent dipolarity/polarizability and hydrogen-bonding interactions. Contrary to the correlations for $E$ isomer, mostly positive sign of coefficients $s$ and $a$ were obtained for $Z$ isomers, indicating a hypsochromic shift of the absorption maxima. A negative sign of the coefficients $s$ and $a$ for $Z$ isomer, were found for compounds 2-4 and 14-16 with strong electron donor $(\mathrm{OH})$ and electron-acceptor $\left(\mathrm{NO}_{2}\right)$ groups (exception are compounds 14 and 15 ; coefficient $a$ ). These results indicate that directional $\pi$-conjugative electron density shift in the molecule as a whole contribute to stabilization of excited state. It might be a consequence of the long-range transmission of substituent effects, which supports the larger polarization of carbonyl group and, in that way, enhances the hydrogen bonding capabilities of carbonyl oxygen and separation of electronic charges. The highest contribution of the HBD effect to solvatochromic properties was observed for compound 4 (batochromic shifts, Table 4) while similar positive values was found for compounds 6, 7 and 10 (hypsochromic shifts, Table S8).

The positive values of the coefficient $b$ obtained for compounds $\mathbf{2 - 4}$, 11 and 13 for $E$ isomer and 2-5, 7, 12 and 13 for $Z$ isomer, indicate better stabilization of the molecule in the ground state (Tables 4 and S8). It implies that the proton-accepting capabilities of amide nitrogen and carbonyl oxygen $(\mathrm{C} 2=0)$ contributes mostly in the moderate/high extent to the solute stabilization in ground state. The highest values of coefficient $b$ were found for $E$ isomer of compound $\mathbf{1 6}$ ( -2.87 ; Table 4$)$ and for compound 4 in $Z$ isomer (3.66; Table S8). Basically, a deviation from the general trend of the value of the coefficients $s, a$ and $b$ for these compounds (Table 4 ) is a consequence of substituent effect and geometry of investigated compounds. In general, complex influences of solvent properties on $v_{\max }$ change could be interpreted as inconsistent alteration of correlation parameters with respect to solvent and substituent effects, as well as effect of geometrical feature of studied isatin derivatives.

In accordance to study solvent/solute interaction in more detail, the molecular electrostatic potential (MEP) analysis was used to visualize charge distribution over investigated compounds (Figs. S17 and S18). MEP potential at a point in space gives information about the net electrostatic interaction exerted by total charge distribution. This value could be correlative with different molecule properties such as: dipole moments, electronegativity, partial charges and chemical reactivity. An electron density isosurface mapped with electrostatic potential

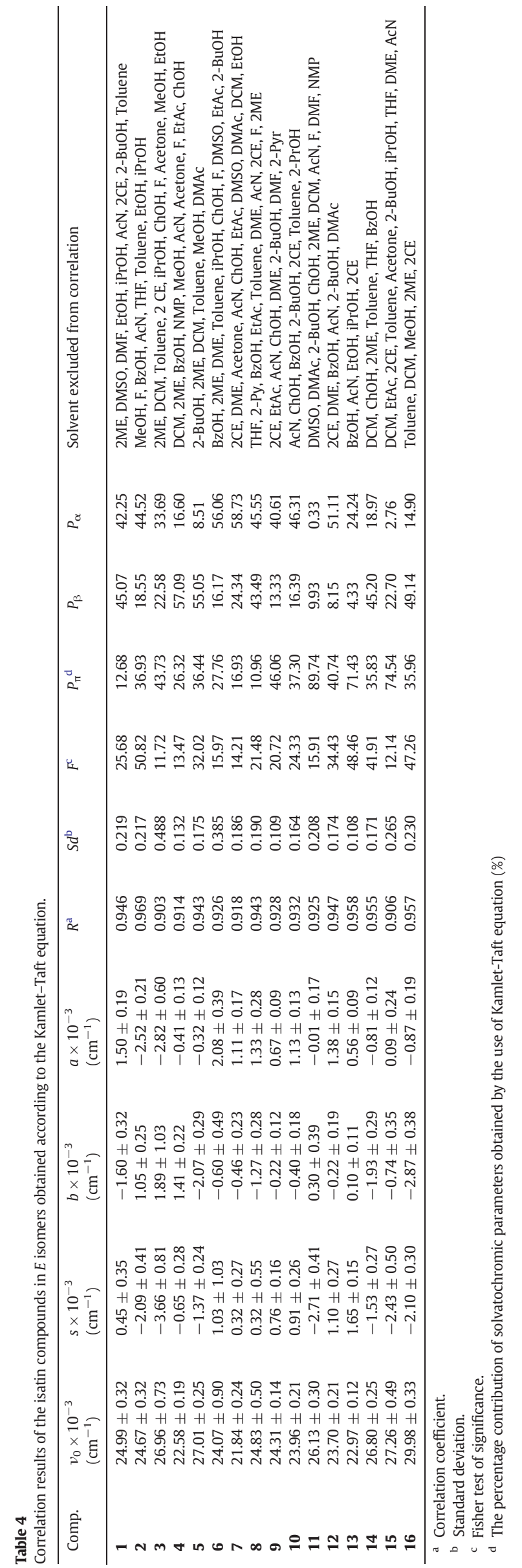


Table 5

Correlation results of the $v_{\max }$ with $\sigma$ constants obtained for $E$ and $Z$ isomers using Hammett (SSP) equation.

\begin{tabular}{|c|c|c|c|c|c|c|c|c|c|}
\hline Form & Solvent & $\rho$ & & $h$ & $R$ & $F$ & sd & $n$ & Compound excluded \\
\hline \multirow[t]{10}{*}{ E } & AcN & $(-2.31 \pm 0.29) \sigma^{2}$ & $(2.57 \pm 0.22) \sigma$ & $24.77 \pm 0.06$ & 0.97 & 72.21 & 0.16 & 11 & $1,7,9,15,16$ \\
\hline & DMSO & $(-2.80 \pm 0.24) \sigma^{2}$ & $(2.40 \pm 0.17) \sigma$ & $24.20 \pm 0.05$ & 0.98 & 96.15 & 0.13 & 11 & $1,3,6,7,16$ \\
\hline & EtOH & $(-5.30 \pm 0.59) \sigma^{2}$ & $(4.95 \pm 0.45) \sigma$ & $24.29 \pm 0.11$ & 0.96 & 59.44 & 0.28 & 12 & $1,4,6,16$ \\
\hline & $2 \mathrm{CE}$ & $(-9.20 \pm 1.44) \sigma^{2}$ & $(8.89 \pm 1.13) \sigma$ & $23.30 \pm 0.27$ & 0.93 & 31.77 & 0.70 & 13 & $1,4,6$ \\
\hline & Acetone & $(-0.90 \pm 0.39) \sigma^{2}$ & $(1.60 \pm 0.28) \sigma$ & $24.10 \pm 0.09$ & 0.94 & 21.72 & 0.21 & 9 & $1,3,5,6,7,15,16$ \\
\hline & Toluene & $(-2.47 \pm 0.63) \sigma^{2}$ & $(4.11 \pm 0.49) \sigma$ & $23.26 \pm 0.13$ & 0.97 & 56.24 & 0.30 & 11 & $1,4,5,6,15$ \\
\hline & THF & $(-3.07 \pm 0.74) \sigma^{2}$ & $(3.84 \pm 0.57) \sigma$ & $23.45 \pm 0.15$ & 0.93 & 26.68 & 0.36 & 11 & $1,3,4,5,16$ \\
\hline & $\mathrm{F}$ & $(-5.13 \pm 0.65) \sigma^{2}$ & $(4.17 \pm 0.50) \sigma$ & $24.25 \pm 0.12$ & 0.94 & 35.73 & 0.32 & 12 & $1,4,8,16$ \\
\hline & DMAC & $(-2.71 \pm 0.39) \sigma^{2}$ & $(2.12 \pm 0.28) \sigma$ & $24.16 \pm 0.08$ & 0.94 & 29.36 & 0.21 & 11 & $3,5,7,12,16$ \\
\hline & 2-Pyr & $(-5.35 \pm 0.69) \sigma^{2}$ & $(4.69 \pm 0.54) \sigma$ & $24.00 \pm 0.13$ & 0.95 & 37.64 & 0.33 & 12 & $1,4,11,16$ \\
\hline \multirow[t]{10}{*}{$Z$} & $\mathrm{AcN}$ & $(3.81 \pm 0.51) \sigma^{2}$ & $(-4.27 \pm 0.37) \sigma$ & $23.74 \pm 0.09$ & 0.98 & 81.44 & 0.19 & 10 & $2,3,4,5,9,14$ \\
\hline & DMSO & $(6.62 \pm 0.90) \sigma^{2}$ & $(-4.41 \pm 0.75) \sigma$ & $23.10 \pm 0.19$ & 0.95 & 27.58 & 0.40 & 9 & $2,3,4,5,6,8,15$ \\
\hline & EtOH & $(2.81 \pm 0.87) \sigma^{2}$ & $(-3.54 \pm 0.60) \sigma$ & $23.88 \pm 0.16$ & 0.94 & 21.06 & 0.31 & 9 & $1,2,3,4,5,14,16$ \\
\hline & $2 \mathrm{CE}$ & $(7.10 \pm 1.33) \sigma^{2}$ & $(-1.49 \pm 1.10) \sigma$ & $21.99 \pm 0.25$ & 0.95 & 30.28 & 0.58 & 9 & $2,3,4,6,8,15,16$ \\
\hline & Acetone & $(8.49 \pm 0.98) \sigma^{2}$ & $(-5.34 \pm 0.76) \sigma$ & $22.27 \pm 0.17$ & 0.93 & 38.21 & 0.48 & 14 & 4,8 \\
\hline & Toluene & $(7.93 \pm 1.16) \sigma^{2}$ & $(-4.40 \pm 0.97) \sigma$ & $21.62 \pm 0.24$ & 0.94 & 27.86 & 0.51 & 10 & $1,2,3,4,6,16$ \\
\hline & THF & $(9.39 \pm 0.90) \sigma^{2}$ & $(-4.84 \pm 0.70) \sigma$ & $21.85 \pm 0.16$ & 0.97 & 61.50 & 0.44 & 12 & $4,8,13,15$ \\
\hline & $\mathrm{F}$ & $(2.84 \pm 0.50) \sigma^{2}$ & $(-1.13 \pm 0.44) \sigma$ & $22.95 \pm 0.09$ & 0.95 & 28.02 & 0.20 & 9 & $3,4,5,7,8,15,16$ \\
\hline & DMAC & $(7.97 \pm 0.94) \sigma^{2}$ & $(-5.27 \pm 0.71) \sigma$ & $22.37 \pm 0.17$ & 0.96 & 36.03 & 0.41 & 9 & $3,4,5,8,9,11,16$ \\
\hline & 2-Pyr & $(4.58 \pm 0.84) \sigma^{2}$ & $(-2.82 \pm 0.65) \sigma$ & $22.73 \pm 0.15$ & 0.93 & 15.01 & 0.36 & 8 & $3,4,6,8,11,12,15,16$ \\
\hline
\end{tabular}

surface depicts the size, shape, charge density and site of chemical reactivity of the molecules. The values of the electrostatic potential at the surface are represented by different colors; red represents regions of most electronegative electrostatic potential (high electron density) favorable sites for HBD solvent/solute interactions; blue represents regions of the most positive electrostatic potential, i.e. region of low electron density favorable for nucleophilic attack (preferential solvent/ solute HBA interactions), and green represents regions of zero potential. Potential increases in the order red $<$ orange $<$ yellow $<$ green $<$ blue. As can be seen from the MEP map (Figs. S17 and S18), negative regions, i.e. most of HBA capabilities, are mainly localized over the carbonyl group $\mathrm{C} 2=0$ and over the methoxy and nitro substituents in the compounds 5-7 and 14-16, respectively. As can be seen from the MEP map of the compounds, the regions having the negative potential are over the electronegative atoms, the regions having the positive potential are over phenyl groups of isatin and over substituent in compounds 6, 9-13 and 15-16 in $E$ isomers. The remaining structures are surrounded by zero potential (Fig. S17). The isatin compounds in $Z$ isomers have the similar positive potential but with lower MEP intensity change with respect to substituents.

\subsection{LFER Analysis of UV Data}

In order to analyze substituent effects on ICT of the investigated isatin derivatives, the LFER principles were applied to the UV-Vis spectral data using Hammett Eq. (4). Non-linear correlations were obtained, and obtained results are given in Table 5 for both $E$ and $\mathrm{Z}$ isomer.
The LFER results reflect the complex and balanced influences of solvent and substituent electronic effects on absorption maxima shifts of both isomers (Table 5). The best correlation fits were obtained using second order polynomial (quadratic) equation. Considering correlation results for both $E$ and $Z$ isomers, it could be observed that the shape of the curves strongly depends on the solvent used (Figs. 4 and S19S22). Most of the curves (parabolas) are not parallel with respect to $y$ axis indicating that there is no proportional response of $v_{\max }$ to electronic substituent effects. Two types of parabolas were obtained: open down for $E$ isomer (Fig. 4a)) and open up for $Z$ isomer (Fig. 4b)). Higher sensitivity of $\nu_{\max }$ to substituent effect was found in protic solvents of isatin derivatives in $E$ isomer. The most significant correlation coefficient was found to be with non-quadratic term which indicates moderate/high extent of substituent effect to the solute stabilization in ground state of $E$ isomer. Highest values of coefficient with $\sigma$ constant were noticed for the solvents which show significant proton-donating capability, i.e. 2CE solvent (8.89), and significantly lower values were found for EtOH (4.95) and F (4.17). These results indicate that HBD solvent effect largely contributes to the stabilization of proton-accepting sites in the ground state of studied compounds. On the other hand, solvent with high relative permittivity showed lower contribution of dipolarity/polarizability effect in ground state. Dipolar aprotic solvents behave as poor anion solvators, with higher potential for stabilization of larger and more dispersible positive charges. In the other word the energy necessary to exert charge separation in either the ground or excited state are relatively similar or of negligible differences, which gives rise to a lower susceptibility to the stabilization expressed by coefficient $s$.
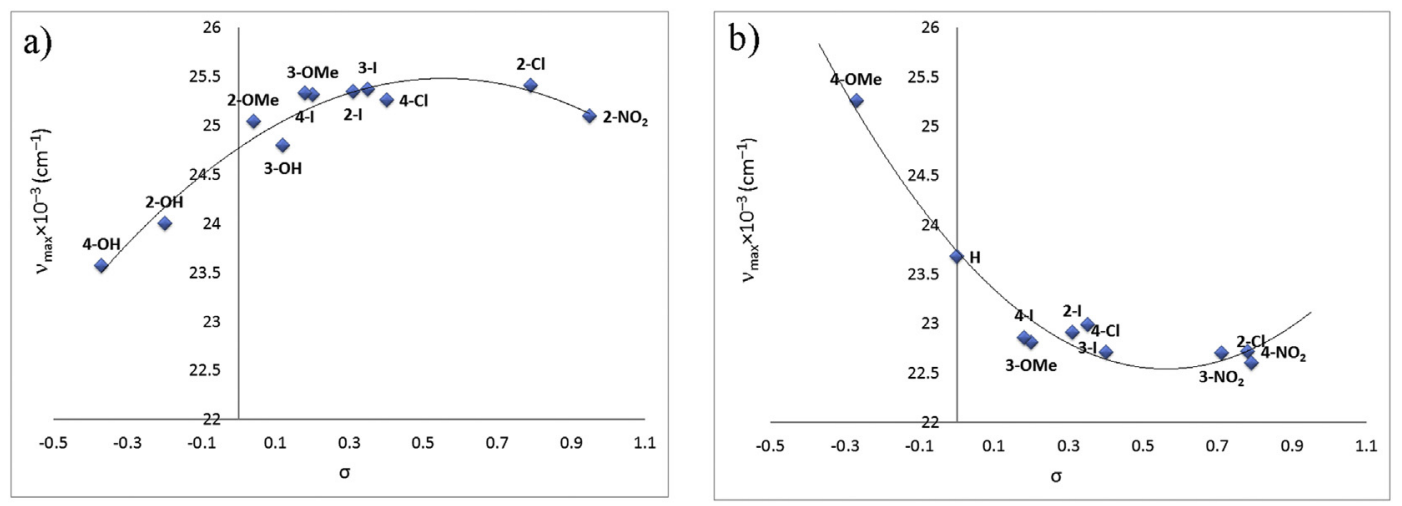

Fig. 4. Correlation of the $v_{\max }$ vs substituent parameters for compounds 1-16 (a) $E$ isomers, b) $Z$ isomers) in AcN. 
Table 6

Correlation results of the NMR data of isatin derivatives in $E$ isomer with $\sigma$ constants using Hammett Eq. (4).

\begin{tabular}{|c|c|c|c|c|c|c|c|c|}
\hline Atom & $\rho$ & & $h$ & $R$ & $F$ & sd & $n$ & Compounds excluded \\
\hline $\mathrm{H}(\mathrm{N})$ & $0.10 \pm 0.01$ & & $10.95 \pm 0.00$ & 0.965 & 120.76 & 0.013 & 11 & $1,3,9,11,15$ \\
\hline $\mathrm{C} 2$ & $(-5.52 \pm 0.80) \sigma^{2}$ & $(-0.48 \pm 0.56) \sigma$ & $164.18 \pm 0.15$ & 0.964 & 71.96 & 0.474 & 14 & $1,3,11,15$ \\
\hline $\mathrm{C} 3$ & $(-5.51 \pm 1.20) \sigma^{2}$ & $(-0.43 \pm 0.89) \sigma$ & $156.05 \pm 0.23$ & 0.936 & 28.39 & 0.646 & 11 & 8,15 \\
\hline $\mathrm{C} 1^{\prime}$ & $(-17.73 \pm 2.64) \sigma^{2}$ & $(14.56 \pm 2.05) \sigma$ & $149.33 \pm 0.51$ & 0.938 & 25.72 & 1.209 & 10 & $7,8,11,15,16$ \\
\hline
\end{tabular}

Opposite shape of correlation curves were found for $Z$ isomer, which indicate higher hypsochromic $v_{\max }$ shift in the compounds with the substituent of high electron-donating or electron-accepting properties. A negative sign of the linear coefficient, obtained in correlations for $Z$ isomer, indicates a batochromic shift of the absorption maxima with the increasing contribution of solvent dipolarity/polarizability and hydrogen-bonding ability. Highest value of the coefficient with linear term was found for acetone $(-5.34)$, while positive coefficient with quadratic term was found for THF (9.39) indicating higher stabilization of the ground state.

\subsection{LFER Analysis of NMR Data}

An appropriate analysis of the ${ }^{13} \mathrm{C}$ NMR chemical shifts has been performed to get a better insight into transmission mode of substituent effect. The general conclusion derived from the data in Table S6 indicates that all substituents from the phenyl ring influence SCS values of the carbon atoms of interest ( $\mathrm{C1}^{\prime}, \mathrm{C} 2$ and $\left.\mathrm{C} 3\right)$ via their electronic effects. The efficacy of substituent effects transmission also depends on conformation of the investigated compounds and the values of torsional angle $\theta$ (Fig. 1 ). Torsion angles $\theta$ were obtained from the geometries optimized by the use of MP2 method with 6-311G(d,p) basis set (Tables 9 and 10).

The analysis of the substituent effect on the NMR data of the carbon atoms of interest, performed by the use of LFER's Eq. (4) with $\sigma$ substituent constants have been applied, and the correlation results obtained for nitrogen $\mathrm{H}$ and $\mathrm{C} 2, \mathrm{C} 3$ and $\mathrm{C}^{\prime}{ }^{\prime}$ carbons are presented in Tables 6 and 7, and Fig. S23.

The observed $\rho$ values indicate different susceptibilities of the SCS to substituent effects. It can be noticed from Tables 6 and 7 that correlations are of good to high quality which means that the change of NMR data reflect sensitivity to electronic substituent effects. Study of the transmission of substituent electronic effects through defined $\pi$-resonance units of investigated compounds showed the contribution of the transmission of electronic effect through isolated $\pi$-electronic unit and overall conjugated system, and their ratio depend on substitution pattern under consideration. The correlation results for $\mathrm{C} 2$ and $\mathrm{C} 3$ in both forms and $\mathrm{C}^{\prime}{ }^{\prime}$ in $E$ form showed nonlinear (parabolic) dependence with respect to substituent effect. Low proportionality constants were found in correlations for $\mathrm{H}(\mathrm{N})$ in both form.

It is apparent that the chemical shifts of $\mathrm{C1}^{\prime}$ show an increased susceptibility and normal substituent effect in $Z$ form (Table 7), while similar behavior and lower effect was found for compounds in $E$ form (Table 6). Reverse substituent effect was observed for electron-donor substituted compounds at $\mathrm{C} 2$ and $\mathrm{C} 3$ in $E$ form, and $\mathrm{C} 2$ in $Z$ form (Tables 6 and 7). The negative sign of reaction constant, $\rho$, means reverse behavior, i.e. the value of SCS decreases although the electron-withdrawing ability of the substituents, measured by $\sigma$ constant, increases. The reverse substituent effect can be attributed to the localized $\pi$-polarization [44], which predominates over the extended $\pi$-polarization (Table 6). Details on the origin of $\pi$-polarization are given in Supplementary material.

\subsection{Comparative LFER Analysis of NMR for Azomethine Carbon of Selected Imino Series}

The study of the mechanism of transmission of electronic substituent effects in an aromatic framework with a side chain, i.e. imino derivatives (Figs. S24 and S25) could give valuable information in the analysis/quantification of the contribution of polar (field/inductive) and polarization effects [45] at the carbon atom of interest. The structural similarity of series 1-7 offers a possibility to compare correlation results in relation to structural difference of heterocyclic structure attached at C3 atom (Fig. 1). The substituent dipole polarizes the vinyl $\pi$-electron resulting in separation of opposite charges at neighboring atoms, which depends on heterocyclic system attached at azomethine carbon. In order to get deeper insights into factors determining such phenomena, a comprehensive analysis of the electronic and structural effect was performed for studied isatin derivatives (series 1) and compared with results obtained for six imino series 2-7 (Figs. S9 and S25) [46-49]. LFER analysis of the NMR data of 4-substituted $\mathrm{N}$ benzylideneanilines (2), $\mathrm{N}$-(phenyl substituted)pyridine-3-aldimines (3), $\mathrm{N}$-(phenyl substituted)pyridine-2-aldimines (4), $\mathrm{N}$-(phenyl substituted)pyridine-4-aldimines (5) and 4-substituted $\mathrm{N}$-[1-(pyridine-3-yl)-ethylidene]anilines ( 6 and 7) were performed. Theoretical calculation showed that $E$ configuration of the optimized structure is a far more stable isomer for both series of ketimines (series 6 and 7) [49].

Results of LFER analysis for the azomethine carbon of series $\mathbf{2 - 7}$, in the form of SSP equation with $\sigma$ constant is presented in Table 8 .

Lower sensitivity on electronic substituent effects for series $\mathbf{6}$ and $\mathbf{7}$ was deduced from the obtained $\rho$ values (Table 8). Normal substituent effects were observed for all studied compounds, except isatin series in $E$ isomer. Two groups of correlation results could be recognized for the azomethine carbon: series $\mathbf{2 - 5}$, and series $\mathbf{6}$ and $\mathbf{7}$. Values of the correlation coefficient $\rho$ for azomethine carbon are similar for series 3-5 with the highest value of 5.80 found for series $\mathbf{5}$ (Table 8). This order indeed reflects ability of electronic density at the azomethine carbon to

Table 8

Correlation of the SCS values for azomethine carbon for series 2-7 with SSP equations.

\begin{tabular}{llllllll}
\hline Series & $\rho$ & $\mathrm{h}$ & $r$ & $F$ & $s$ & $n$ & Ref. \\
\hline $\mathbf{2}$ & $4.50( \pm 0.26)$ & $0.63( \pm 0.13)$ & 0.992 & 293 & 0.34 & 7 & {$[44]$} \\
$\mathbf{3}$ & $5.35( \pm 0.41)$ & $0.44( \pm 0.16)$ & 0.986 & 166 & 0.43 & 7 & {$[45]$} \\
$\mathbf{4}$ & $5.23( \pm 0.33)$ & $0.37( \pm 0.13)$ & 0.990 & 246 & 0.35 & 7 & {$[45]$} \\
$\mathbf{5}$ & $5.80( \pm 0.45)$ & $0.67( \pm 0.18)$ & 0.985 & 163 & 0.48 & 7 & {$[46]$} \\
$\mathbf{6}$ & $2.30( \pm 0.18)$ & $0.31( \pm 0.07)$ & 0.986 & 128 & 0.18 & 7 & {$[47]$} \\
$\mathbf{7}$ & $2.98( \pm 0.28)$ & $0.43( \pm 0.12)$ & 0.979 & 114 & 0.30 & 7 & {$[47]$} \\
\hline
\end{tabular}

Table 7

Correlation results of the NMR data of isatin derivatives in $Z$ isomer with $\sigma$ constants using Hammett Eq. (4).

\begin{tabular}{|c|c|c|c|c|c|c|c|c|}
\hline Atom & $\rho$ & & $h$ & $R$ & $F$ & sd & $n$ & Compounds excluded \\
\hline $\mathrm{H}(\mathrm{N})$ & $0.09 \pm 0.02$ & & $10.84 \pm 0.01$ & 0.933 & 33.50 & 0.017 & 7 & $1,3,5,6,7,9,11,14,16$ \\
\hline $\mathrm{C} 2$ & $(-2.98 \pm 0.69) \sigma^{2}$ & $(0.86 \pm 0.36) \sigma$ & $159.69 \pm 0.14$ & 0.926 & 12.05 & 0.219 & 7 & $1,3,6,10,11,12,13,14,16$ \\
\hline C3 & $(3.18 \pm 0.63) \sigma^{2}$ & $(-0.56 \pm 0.35) \sigma$ & $153.62 \pm 0.14$ & 0.953 & 14.86 & 0.229 & 6 & $1,2,3,5,6,7,11,14,15,16$ \\
\hline $\mathrm{C}^{\prime}{ }^{\prime}$ & $9.28 \pm 1.03$ & & $148.12 \pm 0.26$ & 0.970 & 80.94 & 0.665 & 7 & $3,6,7,8,9,10,14,15,16$ \\
\hline
\end{tabular}


interact with neighboring pyridyl groups which in turn might competitively resonate with phenyl substituent present. Azomethine azomethine carbon suffers from electron deficiency as a consequence of the high electron-accepting properties of "aza" substituent. These results indicate a lower contribution of resonance effect which is likely due to balanced/opposite effects of the substituent and heterocyclic moiety resulting in the higher contribution of the $\pi$-polarization at this carbon in a isatin series in $E$ form.

Delocalization of the lone electron pair in 'aza' group contributes to the decrease of electron density and, hence, the sensitivity of the imino carbon to the field effect is increased. Competitive resonance interaction (structures II-VI; Fig. S26) participates in different extent in NMR shifts change at azomethine carbon. Electron-acceptors suppress to some extent extended $\pi$-delocalization in aniline part of molecule due to favorable aniline type $n$, $\pi$-resonance interaction (structure IV; Fig. S26). Contrary to that, the electron-donors support increased contribution of structures V and VI (Fig. S26). The correlation results for the azomethine carbon (Table 8) indicate that, not only electronic properties of heteroatoms, but also geometrical characteristics influence their specific behavior. Introduction of methyl group, present in series 6 and 7, exerts appropriate steric effect and positive inductive effect supporting imino type resonance [44-47].

Generally it might be concluded that, according to LFER results, (Table 8), transmission of substituent electronic effects through the defined $\pi$-resonance units indicates that these units behave either as isolated or conjugated fragments depending on substituents present. The significance of extended $\pi, \pi$-delocalization through defined $\pi$-resonance units of series 1 (Fig. 1 ) is mainly operative within $\pi$-resonance units with appropriate contribution of $\pi$-polarization.

\subsection{DFT, TD-DFT and Bader's Analysis. Nature of the Frontier Molecular Orbitals}

In order to get deeper insight into solvent and substituent effects on $\nu_{\text {max }}$, i.e. solvatochromism of isomeric forms and conformational changes of the isatin based compounds, quantum-chemical calculations were performed. Geometry optimization and charge density analysis was performed by the use of MP2 method with 6-311G(d,p) basis set. The significant stability of the compounds 1-3, 6-9 and 11-13 in $E$ form were obtained (Table 9).

In addition, the geometries of the investigated molecules were fully optimized by the use of MP2 method, and elements of optimized geometries are given in Tables 10 and S10.

Non-consistent substituent dependent variation and observable differences in the trend of the elements of the optimized geometries of both forms of isatin derivative were noticed (Tables 10 and S10). Some values of bond distances are in the range of statistical errors and

Table 9

Optimized relative energies of isatin derivatives.

\begin{tabular}{|c|c|c|c|c|c|}
\hline Molecule & Isomer & $\begin{array}{l}\text { Energy } \\
\text { (kcal) }\end{array}$ & Molecule & Isomer & Energy (kcal) \\
\hline \multirow[t]{2}{*}{1} & $E$ & 0.0 & 9 & $E$ & 0.0 \\
\hline & $Z$ & 0.288 & & $Z$ & 0.151 \\
\hline \multirow[t]{2}{*}{2} & $E$ & 0.0 & 10 & E & 0.155 \\
\hline & $Z$ & 0.551 & & $Z$ & 0.0 \\
\hline \multirow[t]{2}{*}{3} & $E$ & 0.0 & 11 & E & 0.0 \\
\hline & $Z$ & 0.519 & & $Z$ & 0.280 \\
\hline \multirow[t]{2}{*}{4} & $E$ & 0.347 & 12 & E & 0.0 \\
\hline & $Z$ & 0.0 & & $Z$ & 0.406 \\
\hline \multirow[t]{2}{*}{5} & $E$ & 1.301 & 13 & E & 0.0 \\
\hline & $Z$ & 0.0 & & $Z$ & 0.175 \\
\hline \multirow[t]{2}{*}{6} & $E$ & 0.0 & 14 & E & 1.563 \\
\hline & $Z$ & 0.972 & & $Z$ & 0.0 \\
\hline \multirow[t]{2}{*}{7} & $E$ & 0.0 & 15 & $E$ & 0.545 \\
\hline & $Z$ & 0.612 & & $Z$ & 0.0 \\
\hline \multirow[t]{2}{*}{8} & $E$ & 0.0 & 16 & E & 0.641 \\
\hline & $Z$ & 0.357 & & $Z$ & 0.0 \\
\hline
\end{tabular}

Table 10

Elements of the optimized geometries of investigated compounds in $E$ form, obtained by MP2/6-31G(d,p) method.

\begin{tabular}{llllll}
\hline Comp./subst. & N1-C2 & C2-C3 & C3 $=$ N3 & N3-Ph & $\theta$ \\
\hline $\mathbf{1} / \mathrm{H}$ & 1.3859 & 1.5283 & 1.2893 & 1.4179 & 89.968 \\
$\mathbf{2} / 2-\mathrm{OH}$ & 1.3865 & 1.5258 & 1.2941 & 1.399 & 46.303 \\
$\mathbf{3} / 3-\mathrm{OH}$ & 1.3857 & 1.5283 & 1.2895 & 1.4183 & 84.168 \\
$\mathbf{4} / 4-\mathrm{OH}$ & 1.387 & 1.5277 & 1.2903 & 1.4152 & 71.845 \\
$\mathbf{5} / 2-\mathrm{OMe}$ & 1.3848 & 1.5287 & 1.2907 & 1.414 & 69.815 \\
$\mathbf{6} / 3-\mathrm{OMe}$ & 1.3858 & 1.5282 & 1.2895 & 1.4196 & 87.603 \\
$\mathbf{7} / 4-\mathrm{OMe}$ & 1.387 & 1.5275 & 1.2905 & 1.4144 & 70.794 \\
$\mathbf{8} / 2-\mathrm{Cl}$ & 1.3857 & 1.5284 & 1.2895 & 1.413 & 84.607 \\
$\mathbf{9} / 3-\mathrm{Cl}$ & 1.3854 & 1.5288 & 1.2896 & 1.4155 & 85.65 \\
$\mathbf{1 0} / 4-\mathrm{Cl}$ & 1.3855 & 1.5287 & 1.2896 & 1.4164 & 89.997 \\
$\mathbf{1 1} / 2-\mathrm{I}$ & 1.3865 & 1.5284 & 1.2912 & 1.4129 & 89.634 \\
$\mathbf{1 2} / 3-\mathrm{I}$ & 1.386 & 1.5291 & 1.2909 & 1.4141 & 79.726 \\
$\mathbf{1 3} / 4-\mathrm{I}$ & 1.386 & 1.529 & 1.2906 & 1.4154 & 89.997 \\
$\mathbf{1 4} / 2-\mathrm{NO}_{2}$ & 1.3859 & 1.5273 & 1.2881 & 1.4093 & 87.865 \\
$\mathbf{1 5} / 3-\mathrm{NO}_{2}$ & 1.3852 & 1.5291 & 1.2895 & 1.4117 & 82.155 \\
$\mathbf{1 6} / 4-\mathrm{NO}_{2}$ & 1.385 & 1.529 & 1.2894 & 1.4117 & 89.986 \\
\hline
\end{tabular}

thus they are not suitable for evaluation purpose. In general, low/moderate influences of electronic substituent effects could be noticed. Small variation of N1-C2 bond length indicates low influence of substituent effect, i.e. low contribution of resonance in interaction in amide group $\left(\pi_{3}\right.$-unit; Fig. 1), and low cross-interaction with $\pi_{1}$-unit. Simultaneously, C2-C3 bond length increase in compounds containing strong/moderate electron-donating hydroxy/methoxy substituent in 2- and 4-position of $E$ and $Z$ isomers, excluding compound $\mathbf{5}$ in $E$, and $\mathbf{2}$ and $\mathbf{5}$ in $Z$ form. Low increase was observed for meta-substituted derivatives. Such trend of C2$\mathrm{C} 3$ bond length change indicates that two opposite electron accepting effects operate in the $\pi_{2}$-unit: electron accepting phenyl substituted ring and $\mathrm{C} 2=\mathrm{O}$ carbonyl groups as a response to electronic demand of the electron deficient environment. The normal carbonyl groups polarization is suppressed and causes a slight bond length decrease.

The introduction of both electron-donor and electron-acceptor substituents causes increasing of $\mathrm{C} 3=\mathrm{N} 3$ bond length in all $E$ isomers, except compound $14\left(2-\mathrm{NO}_{2}\right)$. The results are fairly opposite for the compounds in $Z$ isomers where the highest increase of bond length were found for 2and $4-\mathrm{OH} / 2$ - and $4-\mathrm{OCH}_{3}$ substituted compounds. The opposite trend is displayed when electron-acceptor (nitro group) is present. The compounds with ortho-, meta- and para-halogen substituent showed similar values for $\mathrm{N} 1-\mathrm{C} 2$ and $\mathrm{C} 3=\mathrm{N} 3$ bond length in derivatives in $E$ isomers, except compound 11. Presence of a halogen cause decrease of the N3-Ph bond length in all $E$ isomers with largest effect found for ortho-substituted compounds. This result reflect the effect of the extended conjugation operative in the $\pi_{1}$ - and $\pi_{2}$-unit on the $\pi$-electron density shifts toward $\mathrm{C} 2=\mathrm{O}$ carbonyl group and supporting $\mathrm{n}, \pi$-conjugation in the $\pi_{3}$-unit.

A decrease in the N3-Ph bond length, which is a part of the aniline $\pi-$ electronic system ( $\pi_{1}$-unit), contribute to the greater extent of the $n, \pi-$ conjugation. Only, this bond is slightly longer in the electron-donor 3$\mathrm{OH} / 3-\mathrm{OCH}_{3}$ substituted derivatives. On the other hand an interesting trend were noticed for studied compounds in $Z$ isomer: generally, all $\mathrm{N} 3$ - Ph bond length are lower for ortho- and para-substituted ones than in compound 1, while bond increase, for all nitro substituted compounds, were observed. These results imply that the attenuation of the resonance interaction was the process of lower significance in compounds 14-16 as a result of competitive cross-interactions of $\pi_{1}$ - and $\pi_{2}$-units.

Better understanding of the transmission of substituent effects was based on the value of torsion angle $\theta$ (Fig. 1) which contributes to the extended conjugation. The more planar structure provides higher contribution of extended $\pi$-conjugation which in turn produce bathochromic shift in UV spectrum. The values of torsional angle $\theta$ for $E$ isomers are fairly similar, except in 2- and 4-substituted compounds, e.g. 2-OH and $2-\mathrm{OCH}_{3}$, indicating the significance of extended resonance interaction in electron-donor substituted compounds. An electrondonor substituent (hydroxy and methoxy) supports the electron density shift from the $\pi_{1}$-unit (substituted phenyl ring) to the isatin moiety, 
causing the whole molecule planarization in a greater extent. Also, the deviation from the planarity increases with increasing steric effect of phenyl substituent, except for compound 7 in $\mathrm{Z}$ isomer $\left(4-\mathrm{OCH}_{3}\right)$ with almost planar geometry $(\theta=0.01)$. Comparing to unsubstituted $Z$ isomer, larger values of $\theta$ was obtained for halogen and nitro-substituted compounds (Table S10). In these compounds the contribution of $n, \pi-$ conjugation (nitrogen lone pair participation) to overall electronic interaction cause perturbation/disturbance of $\pi$-electron density in the molecule as a whole. The deviation from the planarity increases with decreasing electron acceptor ability of the arylidene substituent.

In the next step the mechanism of electronic excitations and the electron density distribution in ground and excited states was studied by calculation of HOMO/LUMO energies $\left(E_{\mathrm{HOMO}} / E_{\mathrm{LUMO}}\right)$ and $E_{\text {gap }}$ values (Tables S11-S14). TD-DFT results indicated a significant contribution of single particle HOMO to LUMO excitations in ground to first excited state transition, $>60 \%$ for all calculated compounds, except for compound 15 (47\%) and 16 (48\%) (Table S11), for isatins in $Z$ form. Similar results were obtained for compounds in $E$ form (higher contribution than $59 \%$ for all compounds) except compound 11 (40\%) (Table S12).
A lower $E_{\text {gap }}$ values were observed for all compounds in $Z$ form, except of the compound 2. Concerning electron-donor substituents, small influences on $E_{\text {gap }}$ changes could be observed, and the lowest values were found for hydroxy and methoxy-substituted compound, i.e. compounds 4 (5.59) and 7 (5.60), respectively. These results are consistent with largest batochromic shift. According to TD-DFT analysis, the solvent effects on the change of $E_{\mathrm{HOMO}} / E_{\mathrm{LUMO}}$ and $E_{\text {gap }}$ showed small differences between the results obtained for the gas phase (Table S13) and calculations involving solvent DMSO, EtOH and AcN (Table S14).

In order to obtain the data on electronic density distribution, the Bader's charge analysis was performed. Bader's theory of atoms in molecules is useful to define the charge enclosed within the Bader volume as a good approximation of the total electronic charge of an atom. Atom and ring numbering used in Bader's analysis is given in Fig. S27. Difference of atomic charges in the excited and in the ground state $\left(\Delta_{\text {charge }}\right)$ for appropriate atoms, as well as the calculated changes in overall electron density of molecules are given in Tables S14-S16, and Figs. 5 and S28.

The presence of electron-donor substituent (hydroxy and methoxy) in $E$ isomers, cause decreasing of electron density on $\mathrm{C1}^{\prime}$ (except compound $2,2-\mathrm{OH}$ ), imino carbon $\mathrm{C} 3$ and imino nitrogen $\mathrm{N} 3$, comparing

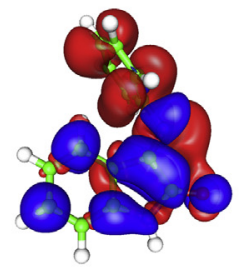

1

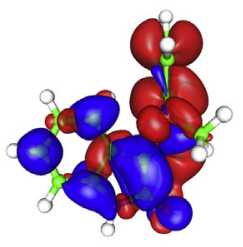

5

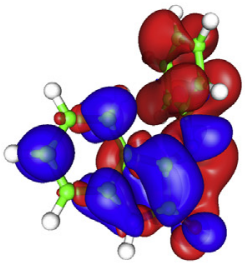

9

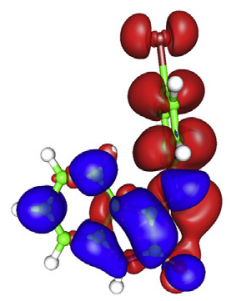

13

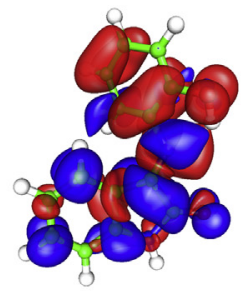

2

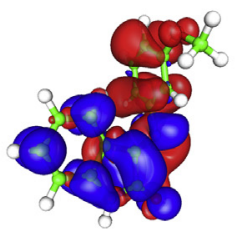

6

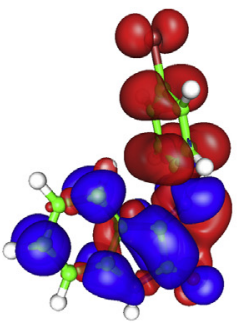

10

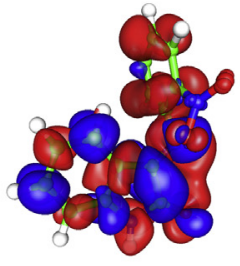

14

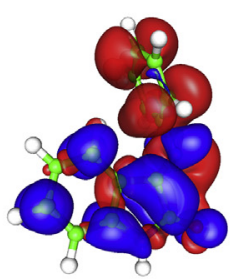

3

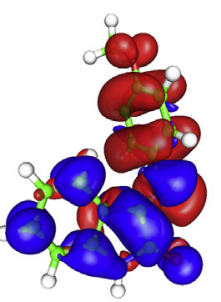

7

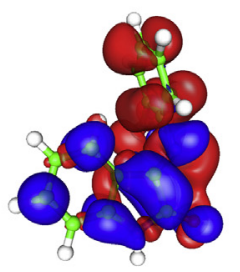

11

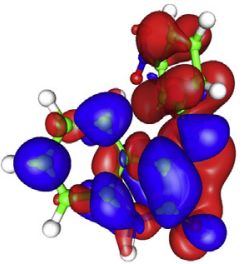

15

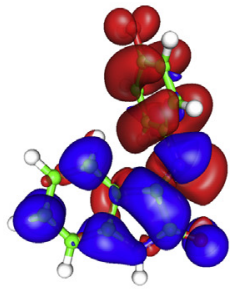

4

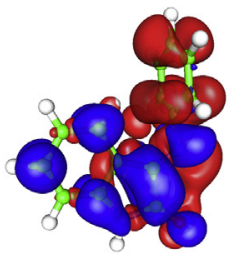

8

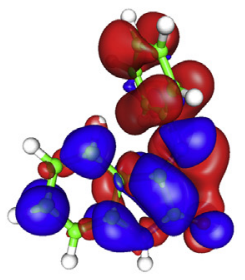

12

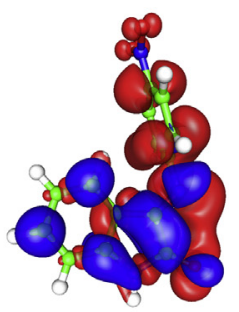

16

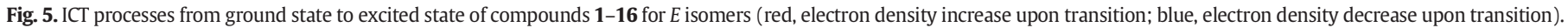


to unsubstituted compound 1 (Fig. 5 and Tables S15-S17). Otherwise, presence of halogen substituents cause an increase of the amount of charge $\left(\Delta_{\text {charge }}\right)$ on $\mathrm{C}^{\prime}{ }^{\prime}$ and imino nitrogen $\mathrm{N} 3$, while imino carbon $\mathrm{C} 3$ has the similar values as compound $\mathbf{1}$. Effect of electron-accepting character of nitro group in $E$ isomers induce reduction of the electron density on $\mathrm{C}^{\prime}{ }^{\prime}$ as well as imino on nitrogen $\mathrm{N} 3$ and increasing electron density on imino carbon $C 3$ relative to compound 1 .

Relative to $Z$ isomer of unsubstituted compound $\mathbf{1}$ value of the amount of charge $\left(\Delta_{\text {charge }}\right)$ on $C^{\prime} 1^{\prime}$ and imino carbon $C 3$ is decreasing if the hydroxy group is in ortho and para position, as well as with methoxy group in para position (Fig. S28 and Tables S15-S17). Oppositely, the electron density on imino nitrogen N3 in presence of 2-OH and 4OMe, compounds $\mathbf{2}$ and 7, respectively. All chloro substituted $Z$ isomers, including compound $13(4-I)$, have a larger amount of charge $\left(\Delta_{\text {charge }}\right)$ on $\mathrm{C}^{\prime}{ }^{\prime}$ in comparison to compound $\mathbf{1}$. If the halogens are in ortho position imino carbon C3 and nitrogen N3 gained $\Delta_{\text {charge. }}$. The presence of electron-accepting nitro group causes decreasing electron density on $\mathrm{C}^{\prime}$ ' and imino carbon C3 while opposite is true for imino nitrogen N3. Detail analyses on the electronic charge change upon transition, presented separately for $E$ and $Z$ isomers in Supplementary material, give an picture on local/overall electron densities shift. In general TD-DFT and LFER results are in good agreement, and reflects influences of the transmission of electronic substituent effects on $\Delta_{\text {charge }}$ change on observed imine bridging group atoms.

Additionally, the intramolecular charge transfer (ICT) were interpreted with the aid of TD-DFT calculations related to the distance between two barycenters of the density depletion and the density increment zones $\left(D_{C T}\right)$ and amount of transferred charge $\left(Q_{C T}\right)$ in the course of excitation. The results of calculated $\mathrm{Q}_{\mathrm{CT}}$ and $\mathrm{D}_{\mathrm{CT}}$ are shown in Table 11 and Figs. 6 and S29. According to the results presented, it could be observed that in both forms distinct ICT processes were observed with electron density transfer from the isatin ring to the substituted phenyl in the course of transition. It is observed that the strongest ICT take place in molecules $14\left(2-\mathrm{NO}_{2}\right)$ for $Z$ isomers and $\mathbf{6}$ (3-OMe) for $E$ isomers, demonstrating transfer of $0.732 \mathrm{e}^{-}$over $2.131 \AA$ Á and $0.776 \mathrm{e}^{-}$ over 2.608 Á, respectively. On the other hand, in molecules 7 (4methoxy substituent), intramolecular charge transfer $0.703 \mathrm{e}^{-}$over 0.156 Á becomes a local process which occurs within imino bridging group (Fig. S29). The variation of substituent patterns clearly indicates that the contributions of both conformational arrangement and donor-accepting character are involved in the ICT mechanism of the investigated molecules.

Decreasing trend, in the order from ortho to para position, of the $\mathrm{Q}_{\mathrm{CT}}$ in $Z$ isomers, for halogen (chloro and iodo) and nitro substituted isatin derivatives, were observed from Table 11 . On the other hand, $\mathrm{Q}_{\mathrm{c}}$ values change of nitro substituted isatin derivatives in $E$ isomers showed

\section{Table 11}

Distance between two barycenters of the density depletion and the density increment zones $\left(\mathrm{D}_{\mathrm{CT}}\right)$ and amount of transferred charge $\left(\mathrm{Q}_{\mathrm{CT}}\right)$.

\begin{tabular}{|c|c|c|c|c|c|}
\hline $\begin{array}{l}\text { Comp./subst. } \\
E \text { isomer }\end{array}$ & $\mathrm{Q}_{\mathrm{CT}},(\mathrm{e})$ & $\mathrm{D}_{\mathrm{CT}},(\hat{A})$ & $\begin{array}{l}\text { Comp./subst. } \\
Z \text { isomer }\end{array}$ & $\mathrm{Q}_{\mathrm{CT}},(\mathrm{e})$ & $\mathrm{D}_{\mathrm{CT},}(\hat{\AA})$ \\
\hline 1/H & 0.762 & 2.363 & $\mathbf{1} / \mathrm{H}$ & 0.669 & 1.93 \\
\hline $2 / 2-\mathrm{OH}$ & 0.624 & 2.27 & $2 / 2-\mathrm{OH}$ & 0.626 & 1.993 \\
\hline 3/3-OH & 0.762 & 2.51 & $3 / 3-\mathrm{OH}$ & 0.684 & 2.172 \\
\hline 4/4-OH & 0.742 & 2.74 & 4/4-OH & 0.644 & 2.149 \\
\hline 5/2-OMe & 0.71 & 2.208 & 5/2-OMe & 0.69 & 2.291 \\
\hline 6/3-OMe & 0.776 & 2.608 & 6/3-OMe & 0.683 & 1.974 \\
\hline 7/4-OMe & 0.737 & 2.78 & 7/4-OMe & 0.703 & 0.156 \\
\hline $\mathbf{8} / 2-\mathrm{Cl}$ & 0.757 & 2.286 & $\mathbf{8} / 2-\mathrm{Cl}$ & 0.708 & 2.142 \\
\hline 9/3-Cl & 0.746 & 2.194 & $\mathbf{9} / 3-\mathrm{Cl}$ & 0.676 & 1.889 \\
\hline $10 / 4-\mathrm{Cl}$ & 0.766 & 2.509 & $10 / 4-\mathrm{Cl}$ & 0.661 & 1.999 \\
\hline 11/2-I & 0.762 & 2.333 & 11/2-I & 0.692 & 2.049 \\
\hline $12 / 3-I$ & 0.728 & 2.121 & $12 / 3-\mathrm{I}$ & 0.674 & 1.871 \\
\hline $13 / 4-\mathrm{I}$ & 0.766 & 2.574 & $13 / 4-\mathrm{I}$ & 0.661 & 2.066 \\
\hline $14 / 2-\mathrm{NO}_{2}$ & 0.674 & 1.062 & $14 / 2-\mathrm{NO}_{2}$ & 0.732 & 2.131 \\
\hline $15 / 3-\mathrm{NO}_{2}$ & 0.711 & 1.819 & $15 / 3-\mathrm{NO}_{2}$ & 0.693 & 1.91 \\
\hline $16 / 4-\mathrm{NO}_{2}$ & 0.729 & 1.881 & $16 / 4-\mathrm{NO}_{2}$ & 0.671 & 1.753 \\
\hline
\end{tabular}

increasing trend. For hydroxy and methoxy substituted derivatives in both $E$ and $Z$ isomers, and chloro and iodo substituted compounds in $E$ isomers the value of calculated $\mathrm{Q}_{\mathrm{CT}}$ for ortho, meta and para position showed non-linear relationship. Specific behavior of hydroxy substituted isatin derivatives in $E$ and $Z$ forms and methoxy in $E$ form was reflected in higher $\mathrm{Q}_{\mathrm{C}}$ values found for meta substituted compounds. On the other hand, methoxy substituted compounds in $\mathrm{Z}$ form and chloro and iodo substituted ones in $E$ form showed the lowest value for meta substituted isatin derivatives.

\subsection{Antimicrobial Studies}

Among studied isatin, it was found in a previous study that $\mathbf{1}(\mathrm{H}), \mathbf{5}$ (2-OMe), 6 (3-OMe), 7 (4-OMe), 8 (2-Cl), 9 (3-Cl), 10 (4-Cl) and 16 (4$\mathrm{NO}_{2}$ ) showed anticonvulsant activity and also demonstrate antidepressant-like activity [50], with the most potent depressant compound $\mathbf{1 6}$ (4- $\left.\mathrm{NO}_{2}\right)$. Also, compound $2(2-\mathrm{OH})$ showed a higher antibacterial and antifungal activity as a ligand in ruthenium(III) complexes [51]. Also, antibacterial activity exhibit of compounds 4 (4-OH), 7 (4-OMe) and $10(4-\mathrm{Cl})$ against sulfate reducing bacteria, while compound $\mathbf{1 0}(4-\mathrm{Cl})$ showed activity with respect to iron bacteria [52].

The isatin derivatives were tested for their antibacterial activity against Staphylococcus aureus + , Listeria monocytogenes + , Shigella sonnei-, Yersinia enterocolitica-, Escherichia coli-, Proteus hauseri-, Pseudomonas Aeruginosa-, Cryptococcus neoformans and Candida albicans. Amoxicillin (AMX) and fluconazole (FLU) where used as a standard for the antibacterial study. The obtained results are presented in Table 12. Compound 7 (4-OMe), 12 (3-I) and $\mathbf{1 3}$ (4-I) were excluded from the antimicrobial analysis due to poor solubility in 10\% DMSO. All other compounds showed activity on at least some of the microbial strains used in the study, in the range of investigated concentrations.

The activity of investigated isatin derivatives against the same microbial strains is similar in most cases, with few exceptions, meaning that different substituents used in this study have little or no effect on antimicrobial activity of the compounds. However, there is a trend of considerable activity of ortho-substituted hydroxy and chloro derivatives and ortho- and para-nitro derivatives against most of the strains. While former are electron-donors and latter an electron-acceptor, they are all electron-negative groups, which may be an important character for the antimicrobial activity. The difference is most pronounced in the case of compound $2(2-\mathrm{OH})$ and compound $\mathbf{3}(3-\mathrm{OH})$ activity against Yersinia enterocolitica, which is $>10$ times greater in former (MIC $=156$ for $2-\mathrm{OH}$ and $\mathrm{MIC}>1250$ for $3-\mathrm{OH}$ ).

There is no difference in activity against G+ and G- bacteria in general, but some strains are more susceptible; Listeria monocytogenes, Shigella sonnei, Yersinia enterocolitica and Proteus hauseri are generally shown to be more susceptible than other bacterial strains.

As for fungal strains, Cryptococcus neoformans was shown to be far more sensitive to compounds than Candida albicans; while MIC values for Candida albicans were similar to those for bacterial strains, the MIC values obtained for Cryptococcus neoformans were, in some cases, even $100 \times$ times greater (compound 2; 2-OH and compound 11; 2-I, MIC $=0.019)$. Compound $3(3-\mathrm{OH}), 4(4-\mathrm{OH}), 8(2-\mathrm{Cl}), 14\left(2-\mathrm{NO}_{2}\right), 16(4-$ $\mathrm{NO}_{2}$ ) also showed prominent antifungal activity against this opportunistic human pathogen ( $\mathrm{MIC}=0.038$ ).

The overall activity of the compounds was most pronounced against the fore mentioned Cryptococcus neoformans. Compound $\mathbf{2}(2-\mathrm{OH})$ and $8(2-\mathrm{Cl})$ showed best activity against Candida albicans $(\mathrm{MIC}=0.313)$ of all investigated compounds. The obtained results suggest necessity of further use of other substituents present on phenyl or heterocyclic ring of the isatin derivatives to be tested.

\subsection{Quantitative Structure-Activity Relationship (QSAR)}

To explore the structural motifs important for the antimicrobial activity of compounds 1-16, we aimed to generate three QSAR models 


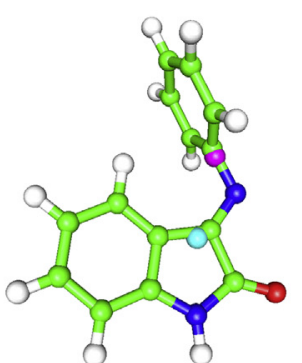

1

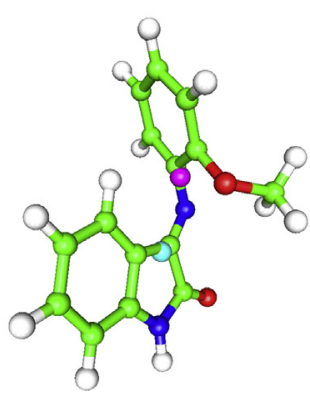

5

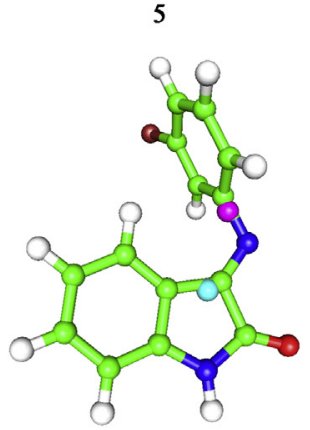

9

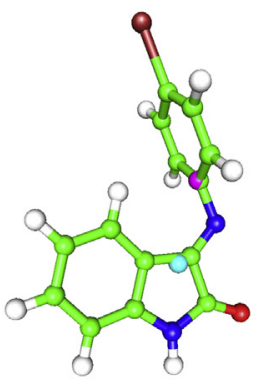

13

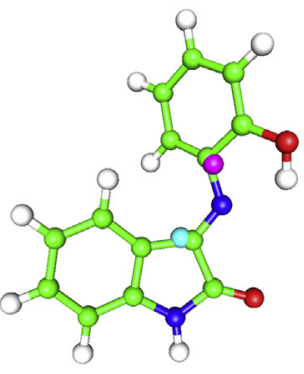

2

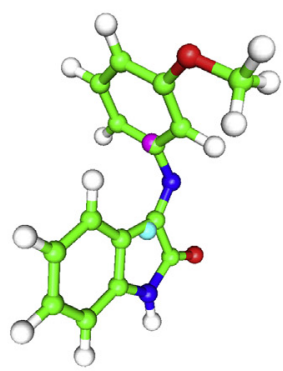

6

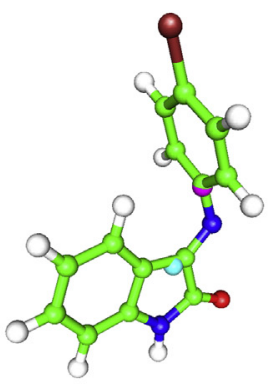

10

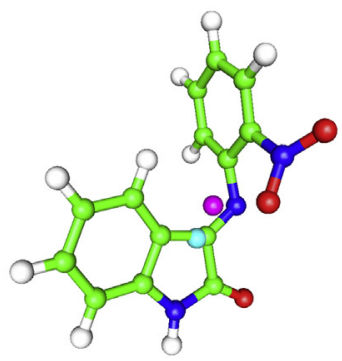

14

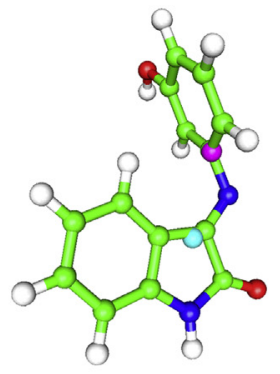

3

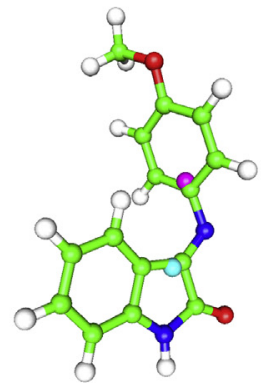

7

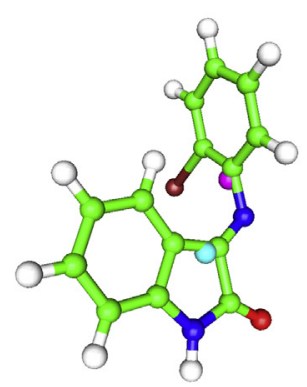

11

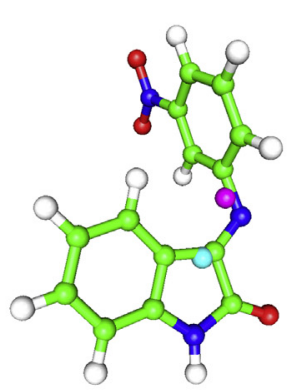

15

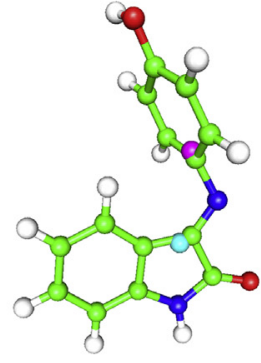

4

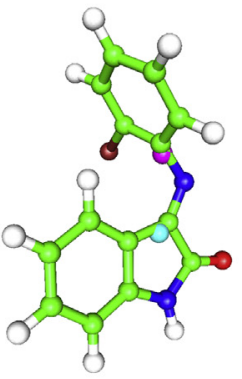

8

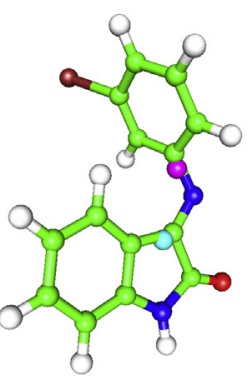

12

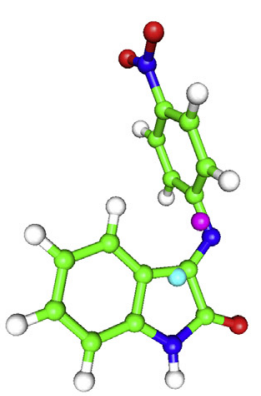

16

Fig. 6. ICT in compounds 1-16 for $E$ isomers. Positions of barycenters for charge loss (cyan circle) and charge gain (violet circle) upon transition.

Table 12

MIC values of visatin derivatives against investigated microbial strains $(\mu \mathrm{g} / \mathrm{mL})$.

\begin{tabular}{|c|c|c|c|c|c|c|c|c|c|c|c|c|c|c|c|c|c|c|}
\hline Compound/microbial strain & 1 & 2 & 3 & 4 & 5 & 6 & 7 & 8 & 9 & 10 & 11 & 12 & 13 & 14 & 15 & 16 & AMX & FLU \\
\hline S. aureus & 1250 & 1250 & 1250 & $>1250$ & 1250 & 1250 & - & 1250 & 1250 & $>1250$ & 1250 & - & - & 1250 & $>1250$ & 1250 & 0.17 & \\
\hline L. monocytogenes & 1250 & 313 & $>1250$ & $>1250$ & 1250 & 1250 & - & 313 & 1250 & 1250 & 1250 & - & - & 313 & 1250 & 313 & 0.34 & \\
\hline S. sonnei & 625 & 313 & 1250 & 625 & 625 & 625 & - & 313 & 625 & 1250 & $>1250$ & - & - & 313 & 1250 & 156 & 5.42 & \\
\hline Y. enterocolitica & 1250 & 156 & $>1250$ & 313 & 1250 & 625 & - & 313 & 625 & 1250 & 1250 & - & - & 156 & 1250 & 156 & 10.84 & \\
\hline E. coli & 1250 & 1250 & $>1250$ & $>1250$ & $>1250$ & 1250 & - & 1250 & $>1250$ & $>1250$ & $>1250$ & - & - & 1250 & 1250 & 1250 & 5.42 & \\
\hline Proteus hauseri & 1250 & 313 & $>1250$ & 1250 & 1250 & 1250 & - & 313 & 1250 & 1250 & 156 & - & - & 313 & 1250 & 313 & 2.71 & \\
\hline Pseudomonas aeruginosa & 625 & 1250 & $>1250$ & $>1250$ & $>1250$ & $>1250$ & - & 1250 & $>1250$ & 1250 & 1250 & - & - & 625 & 1250 & 625 & 21.68 & \\
\hline C. neoformans & 156 & 19 & 39 & 39 & 156 & $>1250$ & - & 39 & 156 & 156 & 19 & - & - & 39 & 156 & 39 & & 6.25 \\
\hline C. albicans & 1250 & 313 & $>1250$ & $>1250$ & $>1250$ & $>1250$ & - & 313 & 625 & 1250 & 1250 & - & - & 1250 & 1250 & 313 & & 12.50 \\
\hline
\end{tabular}


Table 13

Statistics of the PCA model generated after 2 FFD cycle (out of 560 variables, 271 were retained).

\begin{tabular}{lllll}
\hline Component & SSX & SSX $_{\text {acc }}$ & VarX & VarX \\
\hline 1 & 49.92 & 49.92 & 45.27 & 45.27 \\
2 & 14.62 & 64.54 & 12.03 & 57.30 \\
3 & 13.24 & 77.78 & 12.92 & 70.22 \\
\hline
\end{tabular}

\section{Table 14}

Statistics of 2LV PLS model applying different CV procedures. Settings: FFD-LV $=2,20 \%$ of dummy variables, 20 randomization cycles, 3 random groups.

\begin{tabular}{llllll}
\hline Component & SSX $_{\text {acc }}$ & SDEC & SDEP & $\mathrm{r}^{2}$ acc & $\mathrm{q}^{2}$ acc \\
\hline 2 LV (LOO) & 64.22 & 0.17 & 0.29 & 0.89 & 0.69 \\
2 LV (LTO) & 64.39 & 0.18 & 0.31 & 0.88 & 0.64 \\
2 LV (RG) & 70.61 & 0.18 & 0.34 & 0.88 & 0.57 \\
\hline
\end{tabular}

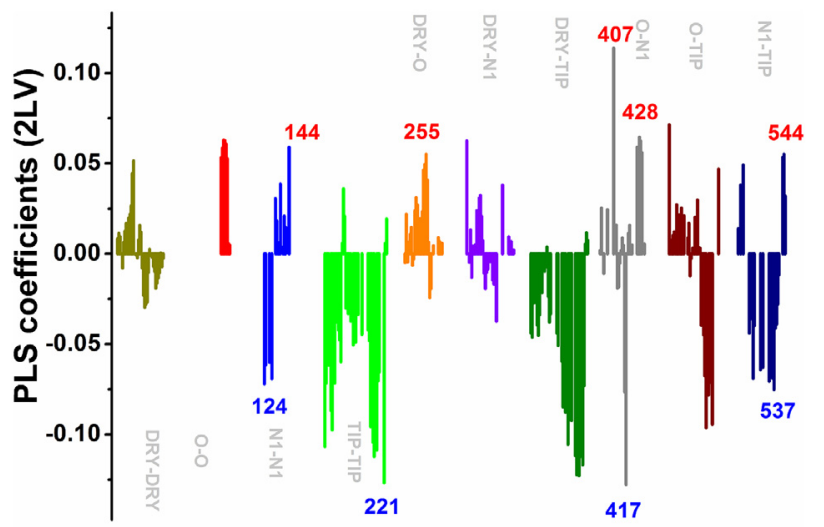

Variable sequential number

Fig. 7. PLS coefficients plot for the model with $2 \mathrm{LV}$, obtained with LOO CV procedure. Variables with positive PLS coefficients are positively correlated with potency, and variables with negative PLS coefficients are associated with structural motifs that decrease the potency. The most informative variables are numbered and further discussed in the manuscript.

taking the MIC values for S. sonnei, Y. enterocolitica and C. neoformans. MIC values, in $\mu \mathrm{g} / \mathrm{mL}$, were first converted to molar units $(M)$, and as a dependent variable for further calculations we took $-\log (\mathrm{MIC})$ values. The statistically significant model is obtained only for the activity of compounds toward C. neoformans.
3.10.1. Model for Antimicrobial Activity of Compounds toward C. neoformans

Principal component analysis (PCA) is performed using the whole set of GRIND-2 descriptors. In order to filter redundant variables from the model, two cycles of fractional factorial design (FFD) were performed, and the statistic of a resulting model is shown in Table 13. Model with 3 principal components (PC) explained $77.78 \%$ of X sum of squares ( $\mathrm{SSX}_{\mathrm{acc}}$ ), and $70.22 \%$ of $\mathrm{X}$ variance (VarX $\mathrm{acc}_{\mathrm{acc}}$ ).

PLS model was made in order to correlate structural features of compounds with antimicrobial potency toward C. neoformans. After filtering of descriptors through 2 cycles of FFD, two latent variables (LV) model with $r^{2}=0.89, q^{2}$ (leave-one-out, LOO cross-validation) $=0.69$, and standard deviation of error of prediction $(\mathrm{SDEP})=0.29$. In order to further determine the predictive power of a model, leave-two-out (LTO) and random group (RG) cross-validation (CV) procedures are applied. Table 14 shows the statistics of PLS models obtained with three CV procedures. In order to eliminate the chance correlation, 10 cycles of $y$ randomization are performed and statistically inferior models are obtained in each run.

The 2LV (LOO) model was used for prediction of a potency of three compounds that were not soluble under experimental conditions ( $\mathbf{7}$, 12, 13). The predicted potency of compound 7 was 3.070 (in pMIC units, which corresponds to $215 \mu \mathrm{g} / \mathrm{mL}$ ). The predicted potency of $\mathbf{1 2}$ and 13 was 181 and $157 \mu \mathrm{g} / \mathrm{mL}$, respectively.

From the PLS coefficients plot (Fig. 7) we identified several variables important for the activity, discriminating more from less potent compounds.

The most informative variables in PLS model are the one that clearly separate more from less potent compounds. Structural motifs associated with the most informative variables are described in Table 15.

The positively correlated variables are depicted on compound $\mathbf{2}$ as a model for more potent compounds (Fig. 8). The variables with the negative influence on potency are depicted on the least potent compound, $\mathbf{6}$ (Fig. 9).

\section{Conclusions}

The $E / Z$ isomer ratios of investigated isatin compounds were estimated from the NMR data, theoretical calculations and deconvolution of UV-Vis spectra. The substituent and solvent effects on the $v_{\max }$ of both isomers of investigated isatin derivatives were successfully evaluated from the experimental data and theoretical calculations. The results of LSER analysis, obtained by using Kamlet-Taft equation, display significant influence and large variation of the contribution of solvent effect on $v_{\max }$ change.

Table 15

The overview of the most important variables and the structural elements. Abbreviations: HBA - H-bond acceptor; HBD - H-bond donor; VV - variable value.

\begin{tabular}{|c|c|c|c|c|}
\hline $\begin{array}{l}\text { Probe } \\
\text { block }\end{array}$ & $\begin{array}{l}\text { Variable } \\
\mathrm{N}^{\circ}\end{array}$ & $\begin{array}{l}\text { Distance } \\
(\AA)\end{array}$ & Impact & Structural elements, comments \\
\hline N1-N1 & 124 & $3.84-4.16$ & - & Two HBA on the molecule at a short distance. One node of this variable is always placed around imino $\mathrm{N}$ atom. \\
\hline N1-N1 & 144 & $10.24-10.56$ & + & $\begin{array}{l}\text { Two HBA groups at larger distance. It is expressed only in compounds } \mathbf{2}-\mathbf{4} \text {. One node is around carbonyl } \mathrm{O} \text { atom, and the other is } \\
\text { around -OH group. }\end{array}$ \\
\hline TIP-TIP & 221 & $16.96-17.28$ & - & Represents two steric hot spots at large distance. The compound 10, 4-Cl derivative, has the highest VV. \\
\hline DRY-O & 255 & $9.92-19.24$ & + & 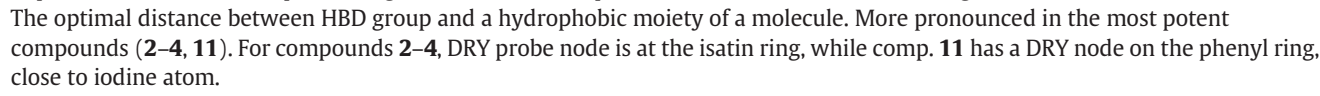 \\
\hline O-N1 & 407 & $4.80-5.12$ & + & 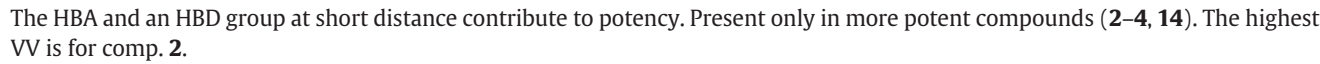 \\
\hline O-N1 & 417 & $8.00-8.32$ & - & $\begin{array}{l}\text { The HBA and HBD group at this distance negatively contribute to potency. Expressed in all less potent and several more potent } \\
\text { compounds. N1 node is associated with imino } \mathrm{N} \text { atom as HBA in all compounds that express this variable. }\end{array}$ \\
\hline O-N1 & 428 & $11.52-11.84$ & + & $\begin{array}{l}\text { A larger distance between HBD and HBA moiety, positively correlated with potency. Expressed only in compounds } \mathbf{2 - 4} \text {. NH from } \\
\text { isatin ring is HBD part of this variable, interacting with O probe. }\end{array}$ \\
\hline N1-TIP & 537 & $10.56-10.88$ & - & $\begin{array}{l}\text { HBA group at this distance from the steric hot spot negatively influences potency. More pronounced in less potent compounds, } \\
\text { with the highest VV for comp. } \mathbf{6} \text {. }\end{array}$ \\
\hline N1-TIP & 544 & $12.80-13.12$ & + & $\begin{array}{l}\text { The optimal distance between HBA and steric hot spot. The molecular edge at isatin ring is associated with TIP node, and OH group } \\
\text { of compounds } \mathbf{2 - 4} \text { with the N1 node. }\end{array}$ \\
\hline
\end{tabular}




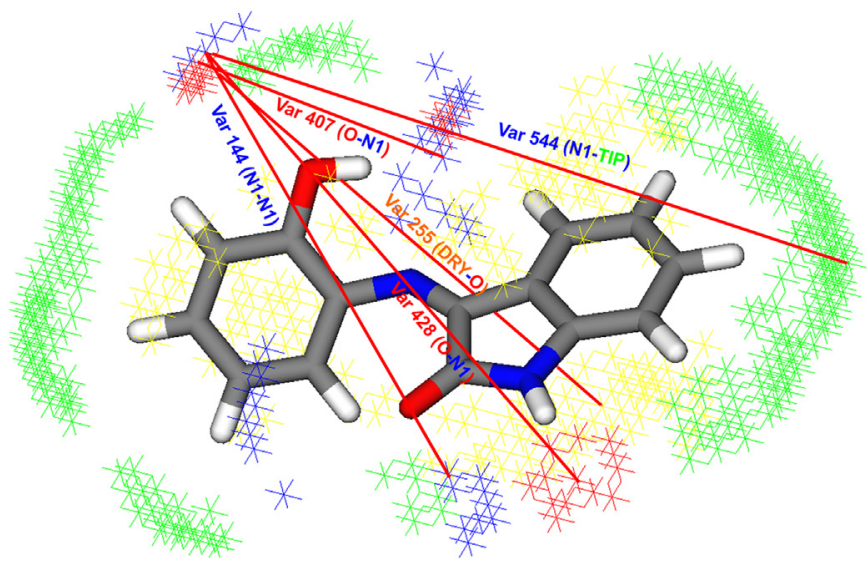

Fig. 8. Structural motifs that contribute to the increased potency of compounds 1-16 depicted on compound 2.

The LFER results reflect the complex and balanced influences of solvent and substituent electronic effects on $v_{\max }$. The LFER analysis of NMR data for $\mathrm{C}^{\prime}$ ' shows the largest effect, while reverse substituent effect, observed for electron-donor substituents $\mathrm{C} 2, \mathrm{C} 3$ and $\mathrm{C}^{\prime}$ in $E$ form, and $\mathrm{C} 2$ in $Z$, was explained by the contribution of $\pi$-polarization.

The inclusion of solvent effects in the TD-DFT calculations demonstrated that both substituent, depending on their position in molecules, and solvent effects significantly affect ICT character. ICT process occurred from the isatin moiety toward substituted phenyl ring with substantial amounts of ICT was found for $\mathbf{1 4}$ in $Z$ isomers and $\mathbf{6}$ in $E$ isomers, demonstrating transfer of $0.732 \mathrm{e}^{-}$over $2.131 \AA$ And $0.776 \mathrm{e}^{-}$over 2.608 Á, respectively.

The investigated isatin derivatives exhibited moderate activity against bacterial strains with the most pronounced activity was achieved against $C$. neoformans. Compounds with hydroxy, nitro group and chlorine in ortho position as well as para nitro showed better activity.

The 3D QSAR model point on hydroxyl groups as substituents important for the potency of compounds toward fungal strain C. neoformans. Replacing $\mathrm{OH}$ with OMe group removes the HBD ability of a substituent that is recognized as important parameter for potency. At the same time, increasing the molecular length by including voluminous substituents in meta or para- position of a phenyl ring decreases the potency of compounds. Imine linker is recognized as a structural motif that reduces the potency of compounds, as it is associated with several variables negatively correlated with potency. Replacing $\mathrm{C}=\mathrm{N}$ with $\mathrm{C}=\mathrm{C}$ or another alkyl linker should lead to the increased potency of these type of compounds toward fungal strain C. neoformans.

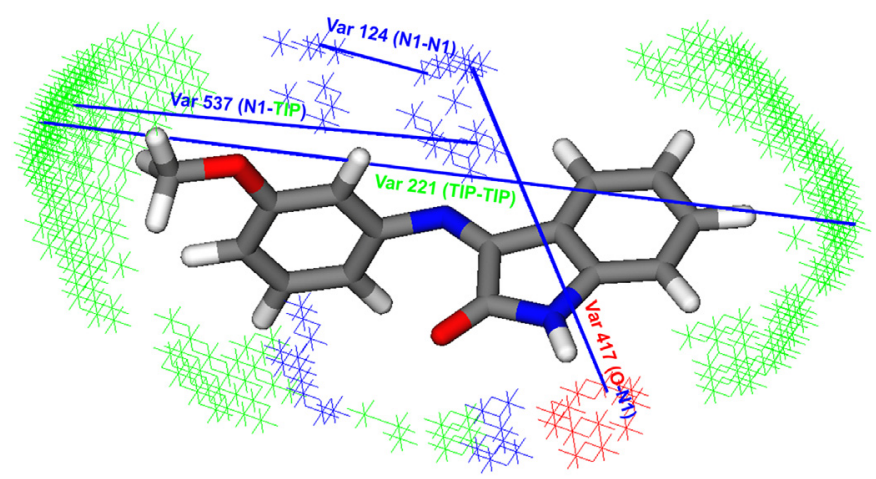

Fig. 9. Structural motifs that contribute to the increased potency of compounds 1-16 depicted on compound $\mathbf{6}$.

\section{Acknowledgements}

This work was supported by the Ministry of Education, Science and Technological development of the Republic of Serbia (Project 172013).

\section{Appendix A. Supplementary Data}

Supplementary data to this article can be found online at https://doi. $\operatorname{org} / 10.1016 / j . s a a .2018 .01 .080$.

\section{References}

[1] I.J. Kang, L.W. Wang, T.A. Hsu, A. Yueh, C.C. Lee, Y.C. Lee, C.Y. Lee, Y.S. Chao, S.R. Shih, J.H. Chern, Isatin- $\beta$-thiosemicarbazones as potent herpes simplex virus inhibitors, Bioorg. Med. Chem. Lett. 21 (2011) 1948-1952, https://doi.org/10.1016/j.bmcl. 2011.02.037.

[2] A.Q. Ali, S.G. Teoh, A. Salhin, N.E. Eltayeb, M.B. Khadeer Ahamed, A.M.S.A. Majid, Synthesis of isatin thiosemicarbazones derivatives: in vitro anti-cancer, DNA binding and cleavage activities, Spectrochim. Acta A Mol. Biomol. Spectrosc. 125 (2014) 440-448, https://doi.org/10.1016/j.saa.2014.01.086.

[3] S.S. Swathy, R. Selwin Joseyphus, V.P. Nisha, N. Subhadrambika, K. Mohanan, Synthesis, spectroscopic investigation and antimicrobial activities of some transition metal complexes of a [(2-hydroxyacetophenone)-3-isatin]-bishydrazone, Arab. J. Chem. 9 (2012) S1847-S1857, https://doi.org/10.1016/j.arabjc.2012.05.004.

[4] K. Kumar, M. Kamboj, K. Jain, D.P. Singh, Spectroscopic and antibacterial studies of new octaazamacrocyclic complexes derived from carbohydrazide and isatin, Spectrochim. Acta A Mol. Biomol. Spectrosc. 128 (2014) 243-247, https://doi.org/ 10.1016/j.saa.2014.02.128.

[5] K. Kumar, S. Carrère-Kremer, L. Kremer, Y. Guérardel, C. Biot, V. Kumar, 1 H -1,2,3Triazole-tethered isatin-ferrocene and isatin-ferrocenylchalcone conjugates: synthesis and in vitro antitubercular evaluation, Organometallics 32 (2013) 5713-5719, https://doi.org/10.1021/om301157z.

[6] M. Ahmad, H. Pervez, S. Zaib, M. Yaqub, M.M. Naseer, S.U. Khan, J. Iqbal, Synthesis, biological evaluation and docking studies of some novel isatin-3hydrazonothiazolines, RSC Adv. 6 (2016)https://doi.org/10.1039/c6ra10043k.

[7] A.P. Nikalje, A. Ansari, S. Bari, V. Ugale, Synthesis, biological activity, and docking study of novel isatin coupled thiazolidin-4-one derivatives as anticonvulsants, Arch. Pharm. (Weinheim, Ger.) 348 (2015) 433-445, https://doi.org/10.1002/ardp. 201500020.

[8] R.A. Rane, S. Karunanidhi, K. Jain, M.H. Shaikh, G. Hampannavar, R. Karpoormath, A Recent Perspective, On discovery and development of diverse therapeutic agents inspired from isatin alkaloids, Curr. Top. Med. Chem. 27 (2015) 1262-1289, https:// doi.org/10.2174/1568026615666150915112334.

[9] A. Nitti, M. Signorile, M. Boiocchi, G. Bianchi, R. Po, D. Pasini, Conjugated thiophenefused isatin dyes through intramolecular direct arylation, J. Organomet. Chem. 81 (2016) 11035-11042, https://doi.org/10.1021/acs.joc.6b01922.

[10] P. Pakravan, S. Kashanian, M.M. Khodaei, F.J. Harding, Biochemical and pharmacological characterization of isatin and its derivatives: from structure to activity, Pharmacol. Rep. 65 (2013) 313-335, https://doi.org/10.1016/S1734-1140(13) 71007-7.

[11] C.S. Marques, A.J. Burke, Enantioselective rhodium(I)-catalyzed additions of arylboronic acids to $N-1,2,3$-triazole-isatin derivatives: accessing $N-(1,2,3-$ triazolmethyl)-3-hydroxy-3-aryloxindoles, ChemCatChem 8 (2016) 3518-3526, https://doi.org/10.1002/cctc.201600901.

[12] Y. Vélez, C. Díaz-Oviedo, R. Quevedo, Kinetic and thermodynamic control in $\beta$-phenylethylamines reaction with isatin, J. Mol. Struct. 1133 (2017) 430-435, https://doi. org/10.1016/j.molstruc.2016.12.039.

[13] Q.X. Guo, Y.W. Liu, X.C. Li, L.Z. Zhong, Y.G. Peng, Enantioselective and solvent-controlled diastereoselective mannich reaction of isatin imines with hydroxyacetone: synthesis of 3-substituted 3-aminooxindoles, J. Organomet. Chem. 77 (2012) 3589-3594, https://doi.org/10.1021/jo202585w.

[14] P. Davidovich, D. Novikova, V. Tribulovich, S. Smirnov, V. Gurzhiy, G. Melino, A. Garabadzhiu, First X-ray structural characterization of isatin Schiff base derivative. NMR and theoretical conformational studies, J. Mol. Struct. 1075 (2014) 450-455, https://doi.org/10.1016/j.molstruc.2014.07.008.

[15] K. Jakusová, M. Cigáň, J. Donovalová, M. Gáplovský, R. Sokolík, A. Gáplovský, Light initiated $\mathrm{E}-\mathrm{Z}$ and Z-E isomerization of isatinphenylsemicarbazones: tautomeric equilibrium effect, J. Photochem. Photobiol. A Chem. 288 (2014) 60-69, https:// doi.org/10.1016/j.jphotochem.2014.05.004.

[16] M. Cigáň, M. Gáplovský, K. Jakusová, J. Donovalová, M. Horváth, J. Filo, A. Gáplovský, Isatin N2-diphenylhydrazones: new easily synthesized Vis-Vis molecular photoswitches, RSC Adv. 5 (2015) 62449-62459, https://doi.org/10.1039/ C5RA06625E.

[17] D.R. Brkić, A.R. Božić, V.D. Nikolić, A.D. Marinković, H. Elshaflu, J.B. Nikolić, S. Drmanić, Solvatochromism of isatin based Schiff bases: an LSER and LFER study, J. Serb. Chem. Soc. 81 (2016) 979-997, https://doi.org/10.2298/JSC160119049B.

[18] A. Albert, E.P. Serjeant, No title, Determ. Ioniz. Constants, 2ndChapman and Hall, London 1971, p. 44.

[19] N.R. Filipović, S. Bjelogrlić, A. Marinković, T.Ž. Verbić, I.N. Cvijetić, M. Senćanski, M. Rodić, M. Vujčić, D. Sladić, Z. Striković, T.R. Todorović, C.D. Muller, Zn(II) complex with 2-quinolinecarboxaldehyde selenosemicarbazone: synthesis, structure, interaction studies with DNA/HSA, molecular docking and caspase-8 and -9 independent 
apoptose induction, RSC Adv. 5 (2015) 95191-95211, https://doi.org/10.1039/ C5RA19849F.

[20] M.J. Kamlet, J.L.M. Abbound, R.W. Taft, An examination of linear solvation energy relationships, in: R.W. Taft (Ed.), Prog. Phys. Org. Chem, John Wiley \& Sons, New York 1981, pp. 485-630.

[21] O. Exner, The Hammett equation - the present position, Advances in Linear Free Energy Relationship, Plenum Press, London, 1972.

[22] Y.C. Martin, Exploring OSAR: hydrophobic, electronic, and steric constants C. Hansch, A. Leo, and D. Hoekman. American Chemical Society, Washington, DC 1995. Xix +348 pp. $22 \times 28.5$ cm. Exploring QSAR: fundamentals and applications in chemistry and biology. C. Hansc, J. Med. Chem. 39 (1996) 1189-1190, https://doi. org/10.1021/jm950902o.

[23] Performance Standards for Antimicrobial Susceptibility Testing: 15th Informational Supplement CLSI Document M100-S15PA, USA: Wayne2005 (n.d).

[24] A. Klaus, M. Kozarski, J. Vunduk, N. Todorovic, D. Jakovljevic, Z. Zizak, V. Pavlovic, S. Levic, M. Niksic, LJ.L.D. Van Griensven, Biological potential of extracts of the wild edible basidiomycete mushroom Grifola frondosa, Food Res. Int. 67 (2015) 272-283, https://doi.org/10.1016/j.foodres.2014.11.035.

[25] M.N. Glukhovtsev, A. Pross, M.P. McGrath, L. Radom, Extension of Gaussian-2 (G2) theory to bromine- and iodine-containing molecules: use of effective core potentials, J. Chem. Phys. 103 (1995) 1878-1885, https://doi.org/10.1063/1.469712.

[26] T. Yanai, D.P. Tew, N.C. Handy, A new hybrid exchange-correlation functional using the Coulomb-attenuating method (CAM-B3LYP), Chem. Phys. Lett. 393 (2004) 51-57, https://doi.org/10.1016/j.cplett.2004.06.011.

[27] J. Tomasi, Thirty years of continuum solvation chemistry: a review, and prospects for the near future, Theor. Chem. Accounts 112 (2004) 184-203, https://doi.org/10. 1007/s00214-004-0582-3.

[28] T. Le Bahers, C. Adamo, I. Ciofini, A qualitative index of spatial extent in chargetransfer excitations, J. Chem. Theory Comput. 7 (2011) 2498-2506, https://doi. org $/ 10.1021 / \mathrm{ct} 200308 \mathrm{~m}$

[29] M.J. Frisch, G.W. Trucks, H.B. Schlegel, G.E. Scuseria, M.A. Robb, J.R. Cheeseman, G. Scalmani, V. Barone, B. Mennucci, G.A. Petersson, H. Nakatsuji, M. Caricato, X. Li, H. P. Hratchian, A.F. Izmaylov, J. Bloino, G. Zheng, J.L. Sonnenberg, M. Hada, M. Ehara, K. Toyota, R. Fukuda, J. Hasegawa, M. Ishida, T. Nakajima, Y. Honda, O. Kitao, H. Nakai, T. Vreven, J.A. Montgomery, J.E. Peralta, F. Ogliaro, M. Bearpark, J.J. Heyd, E. Brothers, K.N. Kudin, V.N. Staroverov, T. Keith, R. Kobayashi, J. Normand, K. Raghavachari, A. Rendell, J.C. Burant, S.S. Iyengar, J. Tomasi, M. Cossi, N. Rega, J.M. Millam, M. Klene, J.E. Knox, J.B. Cross, V. Bakken, C. Adamo, J. Jaramillo, R. Gomperts, R.E. Stratmann, O. Yazyev, A.J. Austin, R. Cammi, C. Pomelli, J.W. Ochterski, R.L. Martin, K. Morokuma, V.G. Zakrzewski, G.A. Voth, P. Salvador, J.J Dannenberg, S. Dapprich, A.D. Daniels, O. Farkas, J.B. Foresman, J.V. Ortiz, J. Cioslowski, D.J. Fox, Gaussian 09, Revision D.01, 2013https://doi.org/10.1159/ 000348293.

[30] W. Tang, E. Sanville, G. Henkelman, A grid-based Bader analysis algorithm without lattice bias, J. Phys. Condens. Matter 21 (2009), 84204. https://doi.org/10.1088/ 0953-8984/21/8/084204.

[31] L. Laaksonen, A graphics program for the analysis and display of molecular dynamics trajectories, J. Mol. Graph. 10 (1992) 33-34, https://doi.org/10.1016/0263-7855(92) 80007-Z.

[32] P.J. Goodford, A computational procedure for determining energetically favorable binding sites on biologically important macromolecules, J. Med. Chem. 28 (1985) 849-857, https://doi.org/10.1021/jm00145a002.

[33] M. Pastor, G. Cruciani, I. McLay, S. Pickett, S. Clementi, GRid-INdependent descriptors (GRIND): a novel class of alignment-independent three-dimensional molecular descriptors, J. Med. Chem. 43 (2000) 3233-3243, https://doi.org/10.1021/jm000941m.

[34] Á. Durán, G.C. Martínez, M. Pastor, Development and validation of AMANDA, a new algorithm for selecting highly relevant regions in molecular interaction fields, J. Chem. Inf. Model. 48 (2008) 1813-1823, https://doi.org/10.1021/ci800037t.

[35] J.J.P. Stewart, Optimization of parameters for semiempirical methods V: modification of NDDO approximations and application to 70 elements, J. Mol. Model. 13 (2007) 1173-1213, https://doi.org/10.1007/s00894-007-0233-4.
[36] A. Pedretti, L. Villa, G. Vistoli, VEGA - an open platform to develop chemo-bio-informatics applications, using plug-in architecture and script programming, J. Comput Aided Mol. Des. 18 (2004) 167-173, https://doi.org/10.1023/B:JCAM.0000035186. 90683.f2.

[37] A. González, J. Quirante, J. Nieto, M.R. Almeida, M.J. Saraiva, A. Planas, G. Arsequell, G Valencia, Isatin derivatives, a novel class of transthyretin fibrillogenesis inhibitors, Bioorg. Med. Chem. Lett. 19 (2009) 5270-5273, https://doi.org/10.1016/j.bmcl. 2009.03.004.

[38] J. Banerji, T.K. Lai, B. Basak, A. Neuman, T. Prangé, A. Chatterjee, A novel route to anticonvulsant imesatins and an approach to cryptolepine, the alkaloid from cryptolepis Sp, Indian J. Chem., Sect. B: Org. Chem. Incl. Med. Chem. 44 (2005) 426-429.

[39] N. Tsuchida, S. Yamabe, Reaction paths of tautomerization between hydroxypyridines and pyridones, J. Phys. Chem. A 109 (2005) 1974-1980, https:// doi.org/10.1021/jp040451w.

[40] M. Jovanović, M.K. Miľcić, A.D. Marinković, Solvent and substituent effect on intramolecular charge transfer in 5-arylidene-3-substituted-2, 4-thiazolidinediones, Arab. J. Chem. (2016)https://doi.org/10.1016/j.arabjc.2016.12.013.

[41] G.A.A. Al-Hazmi, N. El Metwally, A series of nickel(II) complexes derived from hydrazide derivatives, electrochemical, thermal and spectral studies, Arab. J. Chem. 10 (2013) S1003-S1013, https://doi.org/10.1016/j.arabjc.2013.01.002.

[42] L. Antonov, S. Stoyanov, Analysis of the overlapping bands in UV-Vis absorption spectroscopy, Appl. Spectrosc. 47 (1993) 1030-1035, https://doi.org/10.1366/ 0003702934415264.

[43] V. Barone, A. Polimeno, Integrated computational strategies for UV/vis spectra of large molecules in solution, Chem. Soc. Rev. 36 (2007) 1724-1731, https://doi.org/ $10.1039 / \mathrm{b} 515155 \mathrm{~b}$

[44] M.P. Rančíć, N.P. Trišović, M.K. Milčić, I.A. Ajaj, A.D. Marinković, Experimental and theoretical study of substituent effect on 13C NMR chemical shifts of 5-arylidene2,4-thiazolidinediones, J. Mol. Struct. 1049 (2013) 59-68, https://doi.org/10.1016/ j.molstruc.2013.06.027.

[45] D.J. Craik, R.T.C. Brownlee, Substituent-effects on chemical-shifts in the sidechains of aromatic systems, Prog. Phys. Org. Chem. John Wiley \& Sons, Inc., Hoboken, NJ, USA 1983, pp. 1-73, https://doi.org/10.1002/9780470171936.ch1.

[46] R. Akaba, H. Sakuragi, K. Tokumaru, Multiple substituent effects on ${ }^{13} \mathrm{C}$ chemical shifts of $\mathrm{N}$-benzylideneanilines. Evidence for substituent-substituent interactions and their implications of conformational changes with substituents, Bull. Chem. Soc. Jpn. 58 (1985) 1186-1195, https://doi.org/10.1246/bcsj.58.1186.

47] B.Ž. Jovanović, M. Mišić-Vuković, A.D. Marinković, V. Vajs, Effect of substituents on the $13 \mathrm{C}$ chemical shifts of the azomethine carbon atom of $\mathrm{N}$-(phenyl substituted) pyridine-3- and -2-aldimines, J. Mol. Struct. 642 (2002) 113-118, https://doi.org/ 10.1016/S0022-2860(02)00403-9.

[48] B.Ž. Jovanović, M. Mišić-Vuković, A.D. Marinković, V. Vajs, Effect of substituents on the ${ }^{13} \mathrm{C}$ chemical shifts of the azomethine carbon atom of $\mathrm{N}$-(phenyl substituted) pyridine-4-aldimines, J. Mol. Struct. 482-483 (1999) 375-378, https://doi.org/10. 1016/S0022-2860(98)00860-6.

[49] M. Rančic, N. Trišovic, M. Miľ̌ic, M. Jovanovic, B. Jovanovic, A. Marinkovic, Linea free-energy relationships applied to the ${ }^{13} \mathrm{C}$ NMR chemical shifts in 4-substituted $\mathrm{N}$-[1-(pyridine-3- and -4-yl)ethylidene]anilines, J. Heterocycl. Chem. 51 (2015) 1442-1451, https://doi.org/10.1002/jhet.1752.

[50] J.Y. Ma, Y.C. Quan, H.G. Jin, X.H. Zhen, X.W. Zhang, L.P. Guan, Practical synthesis, antidepressant, and anticonvulsant activity of 3-phenyliminoindolin-2-one derivatives, Chem. Biol. Drug Des. 87 (2016) 342-351, https://doi.org/10.1111/cbdd. 12668.

[51] S. Arunachalam, N.P. Priya, K. Boopathi, C. Jayabalakrishnan, V. Chinnusamy, Biocidal and catalytic efficiency of ruthenium(III) complexes with tridentate Schiff base ligands, Appl. Organomet. Chem. 24 (2010) 491-498, https://doi.org/10.1002/aoc. 1647.

[52] G. Chen, H. Su, M. Zhang, F. Huo, J. Zhang, X. Hao, J. Zhao, New bactericide derived from isatin for treating oilfield reinjection water, Chem. Cent. J. 6 (2012), 90 https://doi.org/10.1186/1752-153X-6-90. 